\title{
Peripheral Nervous System Involvement in Non-Primary Pediatric Cancer: From Neurotoxicity to Possible Etiologies
}

\author{
Stefano Pro ${ }^{1}\left(\right.$, Luciana Vinti $^{2}$, Alessandra Boni ${ }^{3}{ }^{\circledR}$, Angela Mastronuzzi $^{2}{ }^{\circledR}$, Martina Scilipoti ${ }^{4}$, \\ Margherita Velardi ${ }^{5}$, Anna Maria Caroleo ${ }^{2}$ (D) Elisa Farina ${ }^{3}$, Fausto Badolato ${ }^{5}$, Iside Alessi ${ }^{2}$, Giovanni Di Nardo ${ }^{5}$, \\ Andrea Carai $\left.{ }^{6}{ }^{(}\right)$, Massimiliano Valeriani ${ }^{1}{ }^{(D}$, Antonino Reale ${ }^{4}$, Pasquale Parisi ${ }^{5}{ }^{-}$and Umberto Raucci ${ }^{4, *}$
}

check for updates

Citation: Pro, S.; Vinti, L.; Boni, A.; Mastronuzzi, A.; Scilipoti, M.; Velardi, M.; Caroleo, A.M.; Farina, E.; Badolato, F.; Alessi, I.; et al. Peripheral Nervous System Involvement in Non-Primary Pediatric Cancer: From Neurotoxicity to Possible Etiologies. J. Clin. Med. 2021, 10, 3016. https://doi.org/ $10.3390 / \mathrm{jcm} 10143016$

Academic Editor: Nikolas Herold

Received: 11 June 2021

Accepted: 28 June 2021

Published: 6 July 2021

Publisher's Note: MDPI stays neutral with regard to jurisdictional claims in published maps and institutional affiliations.

Copyright: (c) 2021 by the authors. Licensee MDPI, Basel, Switzerland. This article is an open access article distributed under the terms and conditions of the Creative Commons Attribution (CC BY) license (https:// creativecommons.org/licenses/by/ $4.0 /)$.
1 Child Neurology Unit, Department of Neuroscience, Bambino Gesù Children's Hospital, IRCCS, 00165 Rome, Italy; stefano.pro@opbg.net (S.P.); Massimiliano.valeriani@opbg.net (M.V.)

2 Department of Hematology/Oncology, Gene Therapy and Hematopoietic Transplantation, Bambino Gesù Children's Hospital, IRCCS, 00165 Rome, Italy; luciana.vinti@opbg.net (L.V.); angela.mastronuzzi@opbg.net (A.M.); annamaria.caroleo@opbg.net (A.M.C.); iside.alessi@opbg.net (I.A.)

3 Department of Maternal Infantile and Urological Sciences, Sapienza University of Rome, 00161 Rome, Italy; alessandra.boni@opbg.net (A.B.); elisa.farina@opbg.net (E.F.)

4 Department of Emergency, Acceptance and General Pediatrics, Bambino Gesù Children Hospital, IRCCS, 00165 Rome, Italy; martina.scilipoti@opbg.net (M.S.); antonino.reale@opbg.net (A.R.)

5 Child Neurology, NESMOS Department, Faculty of Medicine and Psychology, Sant'Andrea Hospital, Sapienza University of Rome, 00189 Rome, Italy; margherita.velardi@uniroma1.it (M.V.); faustobadolato23@gmail.com (F.B.); giovannidinardo@uniroma1.it (G.D.N.); pasquale.parisi@uniroma1.it (P.P.)

6 Neurosurgery Unit, Department of Neuroscience, Bambino Gesù Children's Hospital, IRCCS, 00165 Rome, Italy; andrea.carai@opbg.net

* Correspondence: umberto.raucci@opbg.net

\begin{abstract}
Peripheral neuropathy is a well described complication in children with cancer. Oncologists are generally well aware of the toxicity of the main agents, but fear the side effects of new drugs. As chemotherapeutic agents have been correlated with the activation of the immune system such as in Chemotherapy Induced Peripheral Neuropathy (CIPN), an abnormal response can lead to Autoimmune Peripheral Neuropathy (APN). Although less frequent but more severe, Radiation Induced Peripheral Neuropathy may be related to irreversible peripheral nervous system (PNS). Pediatric cancer patients also have a higher risk of entering a Pediatric Intensive Care Unit for complications related to therapy and disease. Injury to peripheral nerves is cumulative, and frequently, the additional stress of a malignancy and its therapy can unmask a subclinical neuropathy. Emerging risk factors for CIPN include treatment factors such as dose, duration and concurrent medication along with patient factors, namely age and inherited susceptibilities. The recent identification of individual genetic variations has advanced the understanding of physiopathological mechanisms and may direct future treatment approaches. More research is needed on pharmacological agents for the prevention or treatment of the condition as well as rehabilitation interventions, in order to allow for the simultaneous delivery of optimal cancer therapy and the mitigation of toxicity associated with pain and functional impairment. The aim of this paper is to review literature data regarding PNS complications in non-primary pediatric cancer.
\end{abstract}

Keywords: pediatric cancer; complications; peripheral nervous system; peripheral neuropathy

\section{Introduction}

Peripheral nervous system (PNS) complications almost always appear during and immediately after chemotherapeutic treatment, while others present months or even years later. Given the growing population of childhood cancer survivors, long-term follow-up and supportive strategies will be of increasing importance to ensure a high quality of life (QOL) after childhood cancer. Neuropathy may also limit the proper administration of 
the chemotherapy regimen, thereby limiting its efficacy, which is why finding strategies to overcome this complication is important. Great attention should be placed on the examination of all patients exposed to neurotoxic agents so that the management of peripheral neuropathy can be initiated quickly.

Additional studies are needed to further understand the mechanisms underlying PNS involvement in pediatric cancer, to improve surveillance strategies, particularly for young children and those with central nervous system (CNS) tumors, and most importantly, to define effective treatment options that will allow the optimization of cancer treatment and the attenuation of toxicity associated with pain and functional impairment.

Chemotherapy is widely recognized as the more common cause of peripheral neuropathy in cancer patients, and neurotoxicity is the second most important cause as a dose-limiting factor of cancer treatment [1]. The recognition of neurotoxicity patterns is important both to differentiate treatment-related symptoms from cancer involvement of the nervous system and to permit assessing dose adjustment or interruption of the treatment in order to prevent further neurologic injury.

Significant expansion of the childhood cancer survivor population correlates with the enlargement of the population potentially at risk for long-term sequelae. In the last few years, genetic risk factors associated with the increase in CIPN in cancer patients were reported, in particular related to pharmacogenomics [2].

The management of PNS involvement in pediatric patients represents the most interesting challenge for the future. Presently, there are no standard protocols for preventive and therapeutic approaches, and rehabilitation strategies are limited for pain management.

The aim of this paper is to review PNS involvement ranging from pathophysiology to clinical presentation, and therapeutic options and outcomes.

\section{Methods}

From a methodological point of view, our contribution is a review and not a systematic review. Papers published up to March 2021 were selected through a computerized literature search using PubMed and ISI Web of Science databases. We conducted a literature search and papers relevant to this review are included in the list of references.

The following terms were entered, individually or in combinations: peripheral nervous system, neuropathy, neurotoxicity, chemotherapy-induced neuropathy, autoimmune peripheral neuropathy, radiation-induced peripheral neuropathy, polyneuropathy, critical illness, enteric neurotoxicity and pediatric cancer/pediatric oncology. The literature has been selected by each author, identifying in theirown opinion the best literature to achieve the aim of the paper.

No restrictions were made on the publication date, study design, and language. A cross-reference search was carried out to identify any further relevant data.

\section{Chemotherapy-Induced Peripheral Neuropathy (CIPN)}

Chemotherapy is the core of treatment in international pediatric cancer protocols. Its toxicities, especially when acute, may interfere not just with the Quality of life (QoL) but also with the optimal delivery of treatment and daily function [3,4].

CIPN, considered just as a transient complication, is a well-recognized and quite frequent neurologic toxicity associated with specific chemotherapy, commonly used in cancer treatment $[3,4]$.

CIPN has been described with various drugs such as vinca alkaloids, platinum compounds, taxanes, and proteasome inhibitors, whichaffect the sensory, motor and/or autonomic components of the PNS [5] (Table 1). 
Table 1. Mechanism of action and clinical features of chemotherapeutic agents, used in pediatric protocols, in chemotherapyinduced peripheral neuropathy (CIPN).

\begin{tabular}{cc}
\hline Chemotherapeutic Agent & Mechanism of Action \\
\hline Platinum compounds & $\begin{array}{c}\text { Damage on the dorsal root ganglion and } \\
\text { consequently a primarily sensory } \\
\text { neuropathy }[6,7] .\end{array}$
\end{tabular}

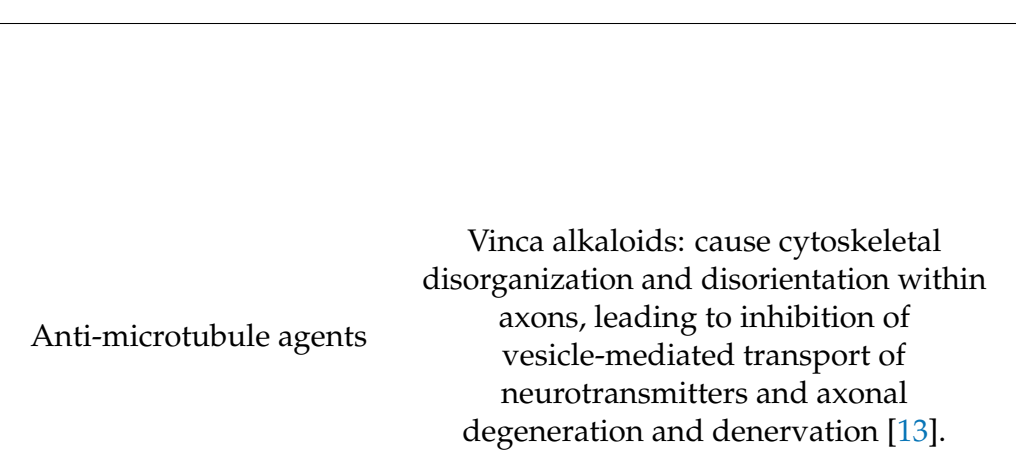

Clinical Features
Cisplatin: causes reversible peripheral sensory
neuropathy, characterized by numbness, tingling, and
paresthesias, sometimes Lhermitte's sign [8-10].
Carboplatin: milder CIPN than cisplatin [11].
Oxaliplatin: cold-induced dysesthesias in the hands and
mouth [12].

Vincristine: axonal, sensorimotor polyneuropathy, which is generally related to cumulative dose. Manifestations comprise reduced deep tendon reflexes, foot and wrist drop, gait abnormalities, and muscle weakness that may be asymmetrical neurotic pain (jaw pain, muscle cramps), paresthesias and dysesthesia. Cranial motor nerves can be affected, causing hoarse voice, ptosis, eye movement disorders, and rarely optic neuropathy. Autonomic nerve involvement may underlie constipation, paralytic ileus, and urinary retention [14-18].

Vinblastine and Vinorelbine: Neurotoxicity is minimal and is less pronounced than that of vincristine; sometimes constipation. If neurotoxicity is present, vincristine may be considered as an alternative chemotherapeutic drug [4,19].

\begin{tabular}{ccc}
\hline Proteasome inhibitors & $\begin{array}{c}\text { Degradation of intracellular proteins, } \\
\text { resulting in accumulation of cytoplasmic } \\
\text { aggregates, including neurofilaments in } \\
\text { neuronal cells [20,21]. }\end{array}$ & $\begin{array}{c}\text { Bortezomib: causes a dose- and length-dependent } \\
\text { sensory axonal peripheral neuropathy [22]. }\end{array}$ \\
Nelarabine & $\begin{array}{c}\text { Nelarabine is an antimetabolite, a } \\
\text { water-soluble pro-drug of } \\
\text { arabinosylguanine nucleotide } \\
\text { triphosphate, a purine deoxyguanosine } \\
\text { analog, leading to the inhibition of DNA } \\
\text { synthesis [23] }\end{array}$ & $\begin{array}{c}\text { Dose-dependent sensory and motor peripheral } \\
\text { neuropathy; also Guillaine-Barrè Syndrome [24,25] }\end{array}$ \\
\hline
\end{tabular}

Traditional chemotherapy preferentially acts on cell division, resulting in DNA damage and strand breakage and interfering with DNA repair and microtubule function. For this reason, it was expected that the PNS, due to its low rate of cellular reproduction and the presence of blood-nerve barriers, would be spared injury. The clinical signs and symptoms of CIPN are caused by axonal damage in the form of a dying-back neuropathy and from damage to dorsal root ganglia cells. This selectivity of damage is probably related to the increased permeability of the blood-nerve barrier at this level [26]. Neuropathy is primarily caused by direct damage to neurons but also by indirect alteration of the surrounding microenvironment, such as localized vascular injury [27]. The role of non-neuronal cells, such as Schwann cells, is still not fully understood. Acute chemotherapy neuropathy is reported in 20-85\% of children treated for acute lymphoblastic leukemia, lymphoma, CNS tumors and non-CNS solid tumors [4,28], which may present with sensory, motor, or autonomic neuron impairments [14,29]. Symptoms of CIPN may disappear on the reduction or discontinuation of the drug in question, but may also persist during therapy and continue long-term after therapy if permanent nerve damage is created [30]. Permanent damage to the structure and function of thePNS, although rarely life-threatening, affects fine motor skills, balance, mobility, endurance, and potentially Quality of Life (QoL) [31-34]. The chemotherapeutic agents responsible for CIPN in the pediatric population are those that act mainly on the microtubule [35]. Anticancer drugs are administered in combination regimens, thus the use of more than one agent makes it difficult to ascribe which is respon- 
sible and exposes the patient to additive neurologic effects [4]. It is important to know that the management of CIPN signs and symptoms, recovery, and the delayed effects of chemotherapy may vary between adult and pediatric patients. Most drugs commonly used for neuropathic pain in adult patients have not been widely studied in children. Additionally, rehabilitation therapies have not been well evaluated in children receiving CIPN-inducing drugs. Thus, both the symptoms of CIPN and methods for alleviating them might be different between these two populations [36].

\subsection{Risk Factors}

The occurrence and gravity of neurotoxicity depend on many factors:

\subsubsection{Treatment Factors}

Dosage: Greater peripheral neurotoxicity has been reported in pediatric population receiving higher cumulative doses of vincristine $\left(>4 \mathrm{~g} / \mathrm{m}^{2}\right)$. [3,27].

Concurrent medication: The administration of azole antifungal agents with vincristine may be present at median time lag up to 30 days [13,37]. One study has reported various patients with atypical neuropathy with hematopoietic colony stimulating factor treatment in association with vincristine [38]. Other possible pharmacokinetic interactions are reported with nifedipine, cyclosporin, carbamazepine and phenytoin. The association of triazole and imidazole antifungal agents is thought to exacerbate vincristine toxicity $[13,37]$. However, azole antifungals themselves are potentially neurotoxic, with interaction due to additive toxicity and not a pharmacokinetic interaction. In fact, peripheral neuropathy has been signaled in subjects exclusively receiving long-term antifungal therapy [37]. Therefore, in consideration of the literature data and regardless of the mechanism, concomitant treatment of vincristine with CYP3A4 inhibitors, in particular azole antifungals, should be avoided.

\subsubsection{Disease Factors}

Progressive rapid weakness, resembling Guillain-Barré syndrome (GBS), has been reported in children with hematological malignancies treated with vincristine, prevailing during the induction phase [39].

\subsubsection{Patient Factors}

Age: Discordant results have been reported on the relationship between vincristineinduced peripheral neuropathy (VIPN) and age. An increased risk of vincristine neurotoxicity has been signaled in older children [14,27,37]. Nevertheless, van de Velde et al. [40], did not confirm a clear association between age and VIPN in pediatrics. These differing results may be due to confounding comorbidities [41].

\subsubsection{Genetic Risk Factors}

With advances in genetic sequencing, multiple genetic mutations have been discovered that may alter chemotherapy neurotoxicity profiles [2]. In particular, in the pediatric literature, research has been conducted mainly on VIPN [3]. The candidate nucleotide polymorphisms can be divided into three categories affecting vincristine metabolism (pharmacokinetics), vincristine toxicity pathways (pharmacodynamics) and SNPs in hereditary neuropathy genes [3].

Genetic alterations in pharmacokinetic pathways: The cytochrome P450 enzyme CYP3A5 "low-expressors" have a greater incidence and severity of vincristine neurotoxicity. Allelic variation in the gene for CYP3A5 results in phenotypic differences in the expression of functional enzymes [3]. In light of the importance of CYP3A5 in vincristine metabolism, several studies have focused on the nonexpressing CYP3A5 genotype (rs776746) [13,37]. Increased occurrence, severity and duration of VIPN with greater dose reductions and omissions in CYP3A5 homozygotes are reported in children. The latter patients had higher metabolite levels 1 hour after dosing and there was a significant inverse association between 
metabolite levels and neuropathy severity. This indicates that the reduced vincristine metabolism in patients not expressing CYP3A5 increases the VIPN. This would also explain the race difference in VIPN, as the percentage of African Americans expressing CYP3A5 is far higher than that of Caucasians (about $60 \%$ vs. 20\%) [42]. However, several independent studies in pediatrics have not demonstrated associations between CYP3A5 and drug concentrations or VIPN [13,42].

Genetic polymorphism in another pharmacokinetic gene (ABCB1) has also been reported to increase neurotoxicity, which explains the difference between Caucasian and African American children [3,15,43].

Genetic alterations in pharmacodynamic pathways: A large genome wide association study established allelic variation of the CEP72 gene, involved in microtubule formation, as being significantly associated with vincristine neuropathy in children.

Interestingly, this variant is less common in African American than Caucasian individuals, providing a second plausible explanation for the inter-race difference in VIPN [13]. A further study that investigated polymorphisms in several pharmacodynamic genes also found allelic variations that may alter the risk of neuropathy [43].

However, many other pharmacokinetic and pharmacodynamic genes have been studied, and the findings require replication in other patient cohorts. The results highlighted the importance of adequate sample sizes and the precise definition of peripheral neuropathy [43].

Genetic susceptibility to hereditary neuropathy: The third group of mutations are those in hereditary neuropathy genes. Early and severe VIPN can occur as inherited underlying susceptibility in the form of a clinical and subclinical hereditary neuropathy such as Charcot-Marie-Tooth disease [3,40]. In the literature, pediatric cases presenting with unexpected severe chemotherapy induced neurotoxicity have been reported, subsequently diagnosed as having a previously unrecognized inherited neuropathy $[44,45]$.

Assessing the impact of preexisting neuropathy on the development and severity of CIPN is controversial because patients with preexisting neuropathy are themselves excluded from clinical trials [46].

\subsection{CIPN of Platinum Compounds}

Platinum agents, above all cisplatin and carboplatin, are utilized in treatment regimens for germ-cell tumors, osteosarcoma, neuroblastoma, CNS tumors, retinoblastoma, and hepatoblastoma. Their toxicity profiles are remarkably different, provoking damage on the dorsal root ganglion and consequently a primarily sensory neuropathy, with consequent reduced sensory nerve action potentials at electroneurogram, reported years after administration [6].

Cisplatin causes reversible peripheral sensory neuropathy, characterized by numbness, tingling, paresthesias, and sometimes Lhermitte's sign, which occurs most commonly when high cumulative doses of cisplatin are administered [8-10]. Symptoms may persist for months or years after the discontinuation of cisplatin. Irreversible loss of high auditory frequencies also appears to be related to a high cumulative dose of cisplatin and generally children under 5 years of age are most affected [7,47].

Cisplatin neurotoxicity may be attributed to its interference with biological enzymes in metabolic pathways. Nevertheless, the incidence and characteristics of cisplatin peripheral neuropathy in children are currently poorly described in the literature [3].

Cisplatin-induced ototoxicity is permanent and progressive, enhanced by concomitant exposure to radiation therapy [48]. The consequences of hearing loss in children are myriad and are especially impactful for patients who are treated when very young. These consequences include the impairment of speech and language acquisition, psychosocial and cognitive development, and educational and vocational achievement. Recently, sodium thiosulfate has been studied as an otoprotectant; however, although it seems to decrease the ototoxicity of cisplatin, its lack of selectivity would give it a tumor-protective property that may limit the curative effect of chemotherapy [49]. 
Platinum-based CIPN interferes with DNA repair mechanisms and causes DNA damage, leading to neuronal apoptosis. The impairment of the physiological replication and transcription of mtDNA, results in the synthesis of abnormal proteins, that cause abnormalities in the mitochondria $[50,51]$.

An altered concentration of $\mathrm{Ca}^{2+}$ may cause the activation of gene expression of neuronal and glial cells, the alteration of membrane excitability, possible neurotransmitters release and activation of calpain which, thanks to altered proteolysis, may determine axonal degeneration [52,53]. Platinum compounds alter the activity of $\mathrm{Na}+, \mathrm{K}+$ and TRP ion channels, resulting in the hyperexcitability of peripheral neurons and induce the activation of glial cells, leading to the attraction and activation of immune cells and the release of pro-inflammatory cytokines. This results in nociceptor sensitization by the modulation of ion channel properties and hyperexcitability of peripheral neurons [54]. The failure of mitochondrial functions has been theorized to underlie what in the clinic is called "coasting" (off-therapy worsening of the symptoms) [50].

Carboplatin-based CIPN is a second generation platinum compound and it is considered less neurotoxic than cisplatin, but the frequent use combined with vincristine, makes it difficult to appreciate its contribution to neurotoxicity. Carboplatin may cause milder peripheral neuropathy than that associated with cisplatin [55] and is generally uncommon [56].

Oxaliplatin-based CIPN is not commonly used in pediatric patients except in the case of second-line therapies, for example in the GemOx regimen. In fact, Oxaliplatin is the most neurotoxic of these compounds and is the only one that also produces an acute neurotoxicity, characterized by cold-induced dysesthesias in the hands and mouth. This is likely due to its effect of transient activation on voltage-gated sodium channels of the peripheral nerves, as a result of the chelation of calcium that increases neuronal excitability [12].

This acute neurotoxicity is temporally independent of cumulative sensory toxicity, however, there is a correlation between the severity and duration of dysesthesiae and the likelihood of developing chronic sensory neuropathy. These compounds result in more prolonged neuropathic symptoms in comparison to other chemotherapy agents, presumably due to the presence of irreversible damage to the dorsal root ganglion sensory neuron $[2,57]$.

\subsection{CIPN of Anti-Microtubule Agents}

\subsubsection{Vinca Alkaloids CIPN}

Vinca alkaloids (vincristine, vinblastine, vindesine, and vinorelbine) act on microtubules, which causes their cytoskeletal disorganization and disorientation within axons, leading to the inhibition of the vesicle-mediated transport of neurotransmitters and axonal degeneration and denervation [13]. Vinca alkaloid exposure is related to an increased risk of motor impairment and platinum exposure is related to an augmented risk of sensory impairment [31,32]. They are often used in the pediatric population and typically cause a length- and cumulative dose-dependent neuropathy, whose incidence increases with more frequent dosing [58].

The different affinity for tubulin (decreasing in order vincristine, vinblastine, vinorelbine) might explain the distinct neurotoxicity [59]. Although vinca alkaloids have a biological effect opposite to that of taxanes, their effect on axonal transport and mitochondria function in neurons appears similar [60]. Indeed, preventing tubulin polymerization from soluble dimers into microtubules, vincristine inhibits both fast and slow axonal transport, which leads to Wallerian degeneration, altered activity of ion channels and the hyperexcitability of peripheral neurons [11].

Vincristine is a key component of treatment regimens for acute lymphoblastic leukemia, medulloblastoma, low-grade glioma, neuroblastoma, Wilms' tumor, rhabdomyosarcoma, lymphoma, Ewing's sarcoma, and retinoblastoma, and is also the agent most frequently associated with peripheral neuropathy in children with a tumor [61,62]. Manifestations com- 
prise reduced deep tendon reflexes [14], foot and wrist drop, gait abnormalities, and muscle weakness that may be asymmetrical $[16,17]$, neurotic pain (jaw pain, muscle cramps), paresthesias and dysesthesia. Cranial motor nerves can be affected, causing a hoarse voice, ptosis, eye movement disorders, and rarely optic neuropathy [18]. Autonomic nerve involvement may underlie constipation, paralytic ileus, and urinary retention [16,17]. In the majority of cases, these symptoms generally recover quickly if the drug is discontinued or the dose is reduced.

Neurophysiological testing shows precocious changes in nerve conduction during chemotherapy affecting approximately $25 \%$ of patients $[3,13]$. These alterations are mainly motor, with reductions in muscle action potentials $[63,64]$ that may be symmetric or asymmetric, involving the lower and upper limbs [16,17]. In childhood cancer survivors, treated with multiple cycles of vincristine, a persistent sensorimotor neuropathy was evident in $20-30 \%$ of patients, suggesting that vincristine related peripheral nerve changes can be long lasting [3,31,65-68].

Vinblastine is a chemotherapy agent frequently used in pediatric regimens for lowgrade gliomas, Hodgkin's lymphoma and desmoid tumors. Despite its structural similarity to vincristine, vinblastine's neurotoxicity is minimal and is less pronounced than that of vincristine [19].

Vinorelbine, used in childhood relapsed or refractory leukemia, Hodgkin's lymphoma, sarcomas, and brain tumors, has a low incidence profile of peripheral neuropathy, mainly causing constipation [4].

\subsubsection{Taxane-Based CIPN}

Taxane-based CIPN is a sensory neuropathy due to dying back axonopathy, typically length-dependent, partially reversible after treatment suspension, and reported in 11-50\% of treated children [69]. Microtubules are important for the development and maintenance of neurons, and serve as a track for anterograde and retrograde axonal transport of synaptic vesicles [70-72]; its disruption leads to Wallerian degeneration [67] with hyperexcitability of peripheral neurons. Nevertheless, taxanes are actually scarcely utilized in childhood cancer and they are not part of the pediatric protocols used

\subsection{CIPN of Proteasome Inhibitors}

A new class of drugs, proteasome inhibitors, is being used in pediatric oncology; in particular, the crucial role is played by bortezomib, used in leukemia and certain types of lymphomas. These drugs express their actions by inhibiting proteasomes, the primary intracellular protein degradation machinery, which results in the accumulation of cytoplasmic aggregates, including neurofilaments in neuronal cells $[20,21]$. Bortezomib causes a dose- and length-dependent sensory axonal peripheral neuropathy. Dorsal root ganglia neuronal cell bodies are the primary target of proteasome inhibition, with peripheral nerve degeneration occurring later. The exact mechanism by which it causes neurotoxicity is not entirely clear, although it seems to play a pivotal role in the alteration of sphingolipid metabolism caused by mutations in serine palmitoyl transferase [22]. The neurotoxicity appears to be more common in adults than children and can enhance the neurotoxicity of vinorelbine or vincristine [73-75].

Ceramide and sphingosine-1 phosphate indeed play an important inflammatory and nociceptive action; in particular, sphingosine- 1 increases neuropathic pain by the release of glutamate from the dorsal horn [76-78]. Bortezomib increases the production of TNF- $\alpha$ and IL-1 $\beta$, with an increase in sphingolipid metabolism within astrocytes [79]. Other mechanisms that seem to be important include nuclear accumulations of ubiquitinated proteins, altered protein transcription in sensory ganglion neurons $[80,81]$, the dysregulation of mitochondrial calcium homoeostasis [20] and the interference with microtubule function that leads to a decreased axonal transport $[73,82]$. Moreover, the blockade of nerve-growthfactor-mediated neuronal survival through the inhibition of nuclear factor $\mathrm{jB}(\mathrm{NFjB})$ might contribute to bortezomib-induced neuropathy. In addition, interfering with mitochondrial 
function, increases the production of ROS [73]. This leads to apoptotic changes, the hyperexcitability of peripheral neurons, the release and elevation of pro-inflammatory cytokines, and therefore to the attraction and activation of T-lymphocytes and monocytes. The new generation of proteasome inhibitors, carfilzomib and ixazomib, seems to have a lower incidence of CIPN [83].

\subsection{Nelarabine CIPN}

Nelarabine is an antimetabolite, a water-soluble pro-drug of arabinosylguanine nucleotide triphosphate, purine analogue used for the treatment of relapsed refrac-tory T-cell acute lymphoblastic leukemia and T-cell lymphoblastic lymphoma after two or more prior treatment regimens, as bridge to stem cell transplantation $[23,84]$. The risk of neurotoxicity may be greater in patients with a history of intrathecal che-motherapy or craniospinal irradiation [85].

Neurological complications were somnolence and neuropathy that occurred typi-cally within the first course of nelarabine therapy and is gradual at onset and reversi-ble [24].

These complications are dose-dependent [86], and mainly be related to prior chemotherapy regimen with other neurotoxic agents [24].

Large fibre peripheral neuropathy (sensory or motor) was found in PNS toxicity [25].

In literature have also been described cases of Guillaine-Barrè Syndrome after receiving high-dose cytarabine in a bone marrow transplant conditioning regimen [24] and cases of irreversible paraplegia $[87,88]$.

Older adolescents have a poor prognosis compared to younger counterparts. In fact, the 5-year overall survival for adolescents is $42-63 \%$, while for children it is $86-89 \%$ [ 89 ].

\subsection{CIPN Clinical Assessment}

All pediatric patients exposed to neurotoxic agents during their cancer treatment should be carefully screened for early signs and symptoms of possible peripheral neuropathy.

The most widely used clinical grading scale in each group is the National Cancer Institute Common Terminology Criteria for Adverse Events, which if administered by well-trained operators, is easy to use and has good reliability [90], although it is subject to underestimation and variable inaccuracies with the age of the patient analyzed $[90,91]$. The modified Balis Pediatric Scale incorporates more child-specific details but has also been shown to have limited sensitivity [92].

The Total Neuropathy Score is commonly used in CIPN, with good reliability and sensitivity $[90,92,93]$. A validated pediatric version of the TNS and its vincristine-specific version, have been created specifically for the ages of 5-18 years [90-92].

Validated rating scales are not available for children younger than 5 years of age nor for children with brain and CNS tumors, with whom CIPN assessment is an additional challenge, as neurological deficits may pre-exist [4]. In general, electrodiagnostic tests reported in the medical literature do not provide additional relevant information to routine clinical management unless other diagnostic hypotheses are at stake or for research purposes $[6,17,18,34,63,64]$. Neurophysiologic tests typically show more extended vincristine motor axonopathy in children than in adults $[67,68]$.

\subsection{CIPN Clinical Neurophysiology}

Neurophysiology provides evidence of nerve alterations with the possibility to detect early functional changes sometimes prior to clinical symptoms, as well as understanding the neuropathological mechanisms and organizing future prevention strategies (Table 2). Neurophysiology is particularly useful in differential diagnosis from CIPN to other neuropathies [94]. Abnormal Nerve Conduction Study (NCS) tends to be associated with large fiber size involvement (proprioception, vibratory sensation and motor activation) and well correlates with the clinical phenotype, giving the opportunity to better characterize CIPN [95]. Typical NCS abnormalities seen in CIPN are characterized from axonal damage: small or absent sensory responses, normal or slightly prolonged distal motor latency, 
small compound motor action potentials, normal or slightly reduced motor conduction velocity, and normal or slightly prolonged F-wave minimum latency. Typically, conduction block/temporal dispersion is not present or may disperse slightly [96].

Table 2. Neurophysiological features of peripheral features from various chemotherapy agents, used in pediatric cancer protocols [46].

\begin{tabular}{|c|c|c|c|c|}
\hline \multirow[t]{2}{*}{ Chemotherapy } & \multicolumn{3}{|c|}{ NCS Findings } & \multirow[t]{2}{*}{ EMG Findings } \\
\hline & $\begin{array}{l}\text { Distal or Proximal } \\
\text { Neuropathy }\end{array}$ & $\begin{array}{l}\text { Axonal or } \\
\text { Demyelinating } \\
\text { Neuropathy }\end{array}$ & $\begin{array}{l}\text { Sensory and/or Motor } \\
\text { Neuropathy }(\mathrm{S} / \mathrm{M})\end{array}$ & \\
\hline Vincristine & $\begin{array}{c}\text { Distal or Distal > } \\
\text { Proximal; }\end{array}$ & $\begin{array}{l}\text { Axonal; prolonged } \\
\text { DML }\end{array}$ & $\mathrm{SM}$ or $\mathrm{S}>\mathrm{M}$ & neurogenic pattern \\
\hline Cisplatin & $\begin{array}{c}\text { Distal; or Distal and } \\
\text { Proximal }\end{array}$ & Axonal & $\mathrm{S}$ & \\
\hline Oxaliplatin & \multicolumn{3}{|c|}{$\begin{array}{l}\text { In acute stage: repetitive motor discharges associated with CMAP; } \\
\text { In chronic stage: distal } S \text { axonal }\end{array}$} & $\begin{array}{l}\text { In acute stage: Fasciculations } \\
\text { and repetitive discharges; In } \\
\text { chronic stage: no chronic } \\
\text { neurogenic pattern }\end{array}$ \\
\hline Bortezomib & & Axonal & $>S$ or $S M$ & \\
\hline Nelarabine & & Axonal; GBS-like & $\mathrm{S}$ or $\mathrm{M}$ & \\
\hline
\end{tabular}

Although some clinical studies identified patients with neuropathy purely based on their symptoms, neurophysiological exams are increasingly incorporated into CIPN assessment protocols [97]. In particular, NCS has been shown to be useful in the early stage of CIPN, identifying high-risk patients. However, in some cases, NCS does not travel parallel to the clinical course and may not change later in the course of treatment [98]. Furthermore, some clinical symptoms (particularly pain) may be seen without abnormalities in NCS [99]. Other literature data, conversely, reported a significant compound sensory nerve action potential amplitude reduction developing prior to clinical symptoms [100]. The combination of symptom and neurophysiological assessment, composite grading scales and functional measures, provides the best overall description of CIPN. Moreover, neurophysiology has shown promising application as an early surrogate biomarker for CIPN detection [100].

Primary involvement of CIPN is a sensory or sensorimotor axonal neuropathy [46] (Table 2). The current gold standard for CIPN, recommended by the International Federation of Clinical Neurophysiology, is conventional NCS [101]. To provide quantitative evidence for the prevention of CIPN and thus study its management, clinical trials that include NCS biomarkers and patient outcome are important.

\subsection{Therapeutic Options and Prevention Approach}

The study of therapeutic approaches in pediatric CIPN is extremely sparse and mostly limited to patients with vincristine-induced neuropathy [4]. Literature data reported a moderate recommendation for treatment with duloxetine.

While a number of study trials have examined potentially neuroprotective therapies for CIPN, a recent review in adults, as reported in the American Society of Clinical Oncology (ASCO) guidelines, referred to a lack of quality [102].

The benefit of duloxetine has not yet been examined with objective assessment tools such as neurophysiological studies.

Tricyclic antidepressants, pyridoxine, pyridostigmine, and a compound topical gel containing baclofen, amitriptyline, and ketamine have been proposed based on their use in other populations with neuropathic pain [102,103]. Of the many potential neuroprotective agents used in adults, the only ones that have been trialed are carbamazepine and glutamic acid for the prevention of CIPN, and intravenous immunoglobulin, pyridoxine/pyridostigmine and gabapentin for treatment, with limited evidence for benefit $[3,46]$.

Gabapentin and pregabalin have been used in various pediatric studies of vincristineinduced neuropathy, but their efficacy has not been unequivocally established [104,105]. In 
the pediatric setting, dose reduction/discontinuation of treatment with the administration of another drug is often considered when VIPN presents (especially if vincristine-related), although there are no clear indications, and the choice is up to the clinician. However, vincristine is a major component of curative therapy, so it should be reinstated or the dose increased if necessary to the limits of tolerance. [40].

Non-steroidal anti-inflammatory drugs, gabapentin, amitriptyline/nortriptyline, as well as opioids are often reliable first-line agents in the management of neuropathic pain in children with cancer, but it has been concluded that randomized controlled trials are desperately needed [106]. However, also recently there are few studies investigating the role of opioids in the treatment of CIPN in children, and no standard protocols are reported in the literature for CIPN treatment [107]. Recently, however, gabapentin and tricyclic antidepressants as first-line therapy agents have been recommended. Methadone, ketamine, and lidocaine may be useful adjuvants in selected patients [108]. As of today, in pediatric settings, dose reduction or treatment interruption is often considered to prevent or treat chemotherapy-induced neuropathy [4].

Despite the fact that drug therapy can attenuate pain symptoms, research also supports the use of nonpharmacologic interventions in children with cancer who develop neuropathy [109]. Early rehabilitation and exercise in CIPN has not been fully undertaken. Physiotherapy and occupational therapy, focused on exercise to maintain strength and function, as in other neuropathic conditions, would generally be considered important [3,46].

Rehabilitation strategies for children with CIPN should focus on improving deficits (postural control, muscle weakness, fine motor skills), support the recovery of motor control, and promote regular physical activity [110]. Loss of sensory function should also be addressed with patient and family education [4].

Tomasello et al. [111] reported, in a preliminary study, that Scrambler Therapy, a non-invasive cutaneous electrostimulation device, could be a promising aid for adolescents with CIPN in pain control. Scrambler Therapy resulted in complete relief or a dramatic reduction in CIPN pain and an improvement in QoL, which is also durable in follow-up. It caused no detected side effects and can be successfully retrained.

CIPN usually progressively worsens, interfering with patients' therapy and QoL, as well as forcing the caregiver to reduce the optimal dose or the frequency of drug administration. As a consequence, the prevention of CIPN is currently considered a crucial issue. As of today, clear guidelines for the prevention of CIPN in the child population are still missing [112]. Of the potential neuroprotective agents, the only ones that have been trialed in the pediatric population are carbamazepine, glutamic acid and amifostine for the prevention of CIPN, and intravenous immunoglobulin, pyridoxine/pyridostigmine and gabapentin for treatment, with limited evidence (Level C) for benefit [3]. However, in a recent review of VIPN (probably, the most well studied CIPN in the pediatric population) has been reported that pyridoxine and pyridostigmine may induce an improvement in symptoms while glutamic acid and glutamine may have a good preventive role [113].

A second phase III trial showed a potential otoprotective role of sodium thiosulfate against cisplatin-induced hearing loss in children with cancer [114]. Calcium and magnesium infusions for oxaliplatin-induced neuropathy have been associated with positive preliminary data, but require further investigation [115]. Poor evidence and additional data are necessary to understand the potential utility of other treatments: acupuncture, acetyl-Lcarnitine, alpha-lipoic acid, L-carnosine, cryo-compression therapy, exercise, goshajinkigan, amifostine and metformin [116]. As of today, in pediatric settings, dose reduction or treatment interruption is often considered to prevent or treat CIPN [4].

\subsection{Long-Term Outcomes}

With the increasing survival of the newer therapeutic schemes, long term CIPNs are emerging.

Primarily in the case of platinum compounds and taxanes, CIPN may last several years after the completion of chemotherapy [117]. On one hand, clinicians often perceive 
CIPN as an acceptable and necessary side effect of life saving therapy; on the other hand, many patients judge these symptoms, which are often underappreciated by the clinicians, as having an important impact on life quality. Indeed, in severe cases, CIPN can lead to paresis, complete immobilization, significant disability and to a higher probability to fall $[118,119]$. Autonomic disorder does not frequently occur but can be disabling.

Up to $30 \%$ of patients in treatment with cisplatin may experience CIPN even after therapy is discontinued. Recovery can take more than a year and is usually incomplete [120]. Oxaliplatin CIPN is an important cause of treatment discontinuation; instead, its recovery is generally faster and more complete $[119,121]$. While platinum based peripheral neuropathy is mostly associated with sensory impairment, patients in treatment with vinca alkaloids present an increased risk of motor impairment [119,120]. Vincristine neuropathy is often dose limiting and sometimes coasting may be experienced; long-term outcomes are quite good, and symptoms are usually reversible despite recovery potentially lasting for many months [122]. In children with acute lymphoblastic leukemia, sequelae can be seen up to several years after treatment conclusion $[67,68]$. Vinorelbine neuropathy usually recovers after discontinuation.

Taxane treatment generally shows, with dose reduction, an improvement in symptoms. CIPN may last for months or years after completing therapy with paclitaxel, although half of patients generally get better over a period of months, often persisting with minor symptoms and no interference with daily life activities [123].

Ixabepilone-based peripheral neuropathy is the cause of treatment interruption in up to $25 \%$ of patients. Symptoms generally get better in a few months with dose reduction or with treatment interruption [124,125], and for this reason it is recommended to reduce the dose at sensory neuropathy grade 2 and stop the treatment at grade 3 [115].

Bortezomib neuropathy is reversible within 3-4 months in the majority of patients with dose reduction or drug discontinuation [21,125].

Clinicians should be aware of the dimensions that this problem can reach and of the fact that cancer survivors may need medical monitoring and treatment for a long time; knowledge of CIPN risk factors and symptoms permits the assessment of the best therapeutical scheme for each patient [126].

\section{Autoimmune Peripheral Neuropathy (APN)}

The pathogenesis of neural cytotoxicity and CIPN [127] is due to inflammation, and drug direct activity $[128,129]$. In particular, chemotherapy induces: an increased production and release of pro-inflammatory cytokines; an upregulation of the expression of chemokines, including CCL2 and CX3CL1-in sensory neurons, this promotes the increase in CCL1, IL-6, IL-1 $\beta$, and IL-15 mRNA expression and consequently macrophage activation and infiltration of the dorsal root ganglia (DRG) in CIPN [52,130]; mitochondrial DNA damage and defects in electron transport chain proteins, leading to mitochondrial dysfunction [131] (Figure 1); and an increase in ROS within cells, which can lead to mitochondrial apoptosis, inflammation, and subsequent nerve degeneration.

ROS can also damage phospholipids, resulting in demyelination, oxidized proteins, and an increase in carbonyl by-products, which can impair antioxidant enzymes, and destroy microtubules. Intracellular ROS can also increase pro-inflammatory mediators leading to peripheral nociceptor over-excitation [132,133].

The damage of peripheral nerves exposes epitopes. As chemotherapeutic agents have been correlated with the activation of the immune system [134], an abnormal response can lead to APN (Table 3). This happens when immunologic tolerance to key antigenic sites on the myelin, axon, nodes of Ranvier or ganglionic neurons is lost. The immune response to an infection/inflammatory event can induce a cross-reaction with peripheral nerve components (myelin and axon of peripheral nerve) because of the sharing of cross-reactive epitopes (molecular mimicry) [135], leading to an acute polyneuropathy. 


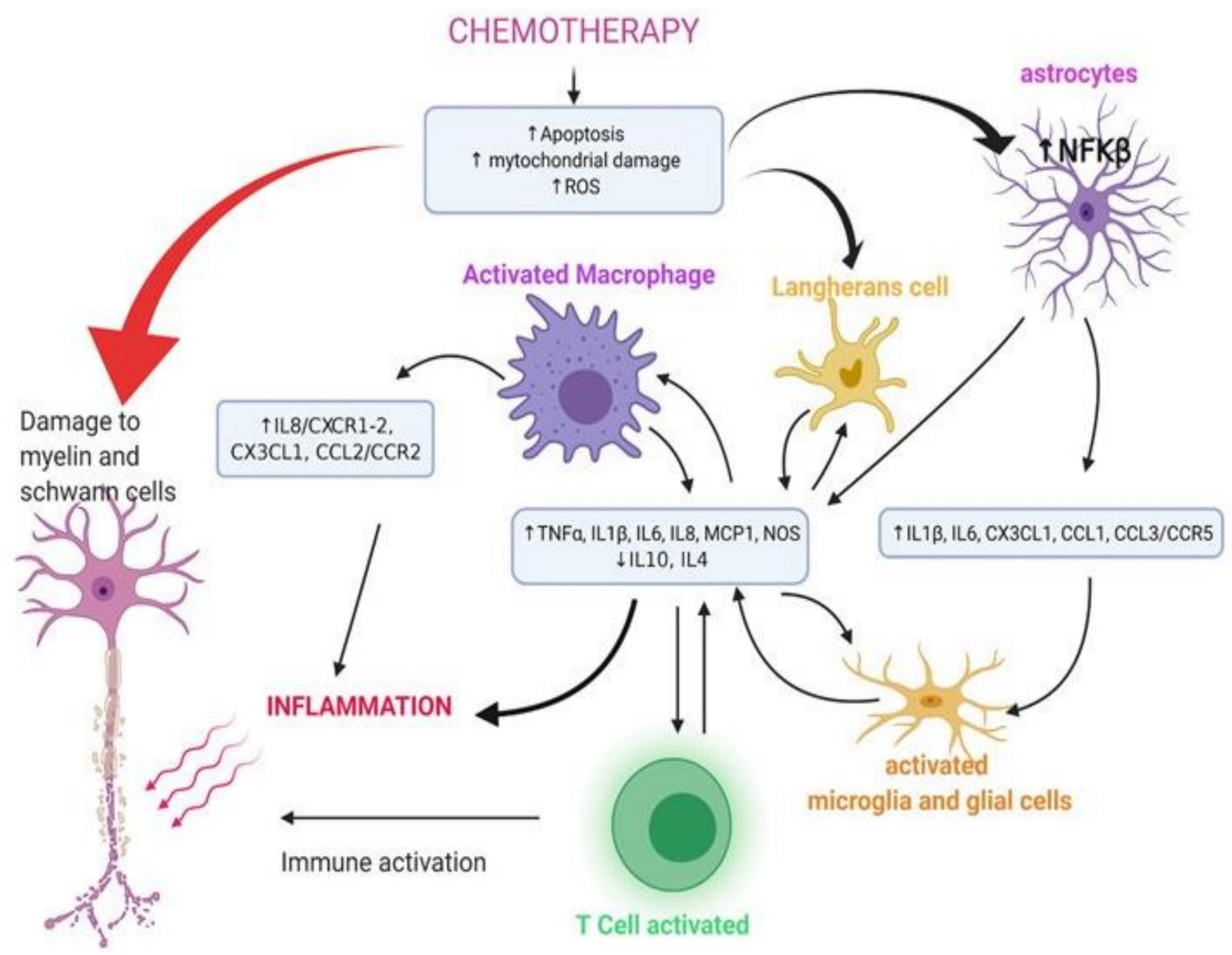

Figure 1. Cells and cytokines involved in chemotherapy damage (created by Biorender.com, accessed on 12 February 2021).

APN in pediatrics include [149] Guillain-Barré syndrome (GBS) and variants, such as Miller Fisher syndrome. Other APNs such as chronic inflammatory demyelinating polyneuropathy (CIDP) [150,151], multifocal motor neuropathy (MMN) [150] and paraproteinemic demyelinating polyneuropathy [151] are almost exclusively found in adults.

Guillain-Barré syndrome rarely occurs after drugs. It is the most frequent form of acquired polyneuropathy caused by demyelination; in particular, it can also be correlated with malignancies, probably due to the depression of the immune system by long-term intensive chemotherapy [152]. GBS is an immune-mediated disorder triggered by an infection/inflammatory event that on one side leads to an activation of immune system cells (such as macrophages, glial cells) and the production of proinflammatory chemokines; this induces inflammation that can result in axonal and myelin sheath damage with consequent demyelination. On the other hand, antibodies against external antigens can lead to complement fixation and may cross-react with specific gangliosides at nerve membranes and subsequently damage Schwann cells [153,154], leading again to demyelination or axonal damage or both [155]. This molecular mimicry, in combination with complement activation, leads to nerve dysfunction and symptoms of GBS. Several of these antiganglioside antibodies are frequently present (35-40\% of cases) in the serum samples obtained during the acute phase and are associated with specific subtypes of GBS (anti-GM1a, antiGM1b, anti-GD1a, and anti-GalNAc-GD1a in acute motor axonal neuropathy (AMAN), and especially anti-GQ1b in Miller Fisher syndrome) [150]. The major forms are acute inflammatory demyelinating polyradiculoneuropathy (AIDP), Miller Fisher syndrome (MFS main features are ophthalmoplegia, ataxia, and areflexia), AMAN, and acute sensorimotor 
axonal neuropathy (AMSAN) (Table 4). Symptoms and signs usually progress within 1 to 2 weeks. Clinically it is manifested by acute distal muscular weakness up to flaccid paralysis, with symmetrical and ascending course, a lack of reflexes and mild to moderate sensory disturbances. Few cases of GBS are associated with platinum compounds in the literature [147,148]. It is an immune-mediated, non-dose-related side effect. Platinum compounds may act as triggers of autoimmunity by inducing an elevation of proinflammatory cytokines (TNF- $\alpha$ and IL-6) and by enhancing anticancer immune responses, which induce an immune reaction towards myelin antigen [146].

Table 3. Autoimmune peripheral manifestations related to chemotherapeutic agents, used in pediatric cancer protocols.

\begin{tabular}{|c|c|c|}
\hline $\begin{array}{c}\text { Chemotherapeutic } \\
\text { Agent }\end{array}$ & $\begin{array}{c}\text { Mechanisms of Immunity } \\
\text { Dysregulation }\end{array}$ & APN Features \\
\hline $\begin{array}{l}\text { Immune checkpoint } \\
\text { inhibitors (ICIs) }\end{array}$ & $\begin{array}{l}\text { ICIs enhance production of cytokines } \\
\text { (IL-6 and IL-17) and produce an alternate } \\
\text { Treg/Th17 with consequent abnormal } \\
\text { T-regulatory (Treg) cell function and } \\
\text { humoral immunity [128-130]. }\end{array}$ & $\begin{array}{l}\text { Demyelination: chronic inflammatory demyelinating } \\
\text { polyneuropathy (CIDP), Guillain-Barrè syndrome and } \\
\text { Miller Fisher variant. Sensorimotor polyneuropathy, } \\
\text { autoimmune myopathy, overlaps of myasthenia gravis with } \\
\text { myositis and/or myocarditis, acute motor and sensory } \\
\text { axonal neuropathy (AMSAN), and myasthenia gravis } \\
\text { (anti-MuSK negative) are also reported [136-141]. }\end{array}$ \\
\hline Vinka alkaloids & $\begin{array}{l}\text { Immunodepression secondary to } \\
\text { intensive chemotherapy [142]. }\end{array}$ & $\begin{array}{c}\text { Acute inflammatory demyelinating } \\
\text { polyradiculoneuropathy: examining findings from nerve } \\
\text { conduction velocity studies and performing lumbar } \\
\text { puncture helps to differentiate between vinca alkaloid } \\
\text { neurotoxicity and acute inflammatory demyelinating } \\
\text { polyradiculoneuropathy [143]. }\end{array}$ \\
\hline Proteasome inhibitors & $\begin{array}{l}\text { Both T-cell and humoral immune attack } \\
\text { against peripheral nerve myelin, } \\
\text { vasculitis-induced nerve ischemia, and } \\
\text { inhibition of signaling support for axons } \\
\text { [144]. }\end{array}$ & $\begin{array}{l}\text { Severe polyradiculoneuropathy. } \\
\text { Cases of demyelinating or mixed axonal-demyelinating } \\
\text { neuropathy, with prominent motor involvement, } \\
\text { albumin-cytological dissociation and lumbar root } \\
\text { enhancement on Magnetic Resonance Imaging have been } \\
\text { reported in the literature }[144,145] \text {. }\end{array}$ \\
\hline
\end{tabular}

Increase in proinflammatory cytokines

(TNF- $\alpha$ and IL-6) and enhancement of anticancer immune responses, which induce an immune reaction towards

Anecdotal cases of Guillain-Barrè syndromes [147,148]. myelin antigen [146].

Table 4. Major form of autoimmune neuropathy and related antibodies.

\begin{tabular}{cc}
\hline Subtype & Antibodies \\
\hline AMAN & Anti-GM1a/b, Anti-GD1a GalNAc-GD1 \\
\hline AMSAN & Anti-GM1 Anti-GD1a Anti-GM1b \\
\hline AIDP & AntiGM2 \\
\hline MFS & Anti-GQ1b \\
\hline
\end{tabular}

\subsection{Immune Checkpoint Inhibitor(ICI)-Induced APN}

Immune checkpoint inhibitors (ICIs) such as ipilimumab, nivolumab, and pembrolizumab act by blocking CTLA4 and/or PD-1/PD-L1 pathways and upregulating the immune system. Normally, these receptor ligand interactions give a "turn off" message, which which orders T cells not to attack the tumor [156]. ICIs prevent CTLA-4 or PD-1 from binding to their respective receptors, and consequently inhibition signaling is blocked, thus T lymphocytes are free to kill cancer cells (Figure 2). 


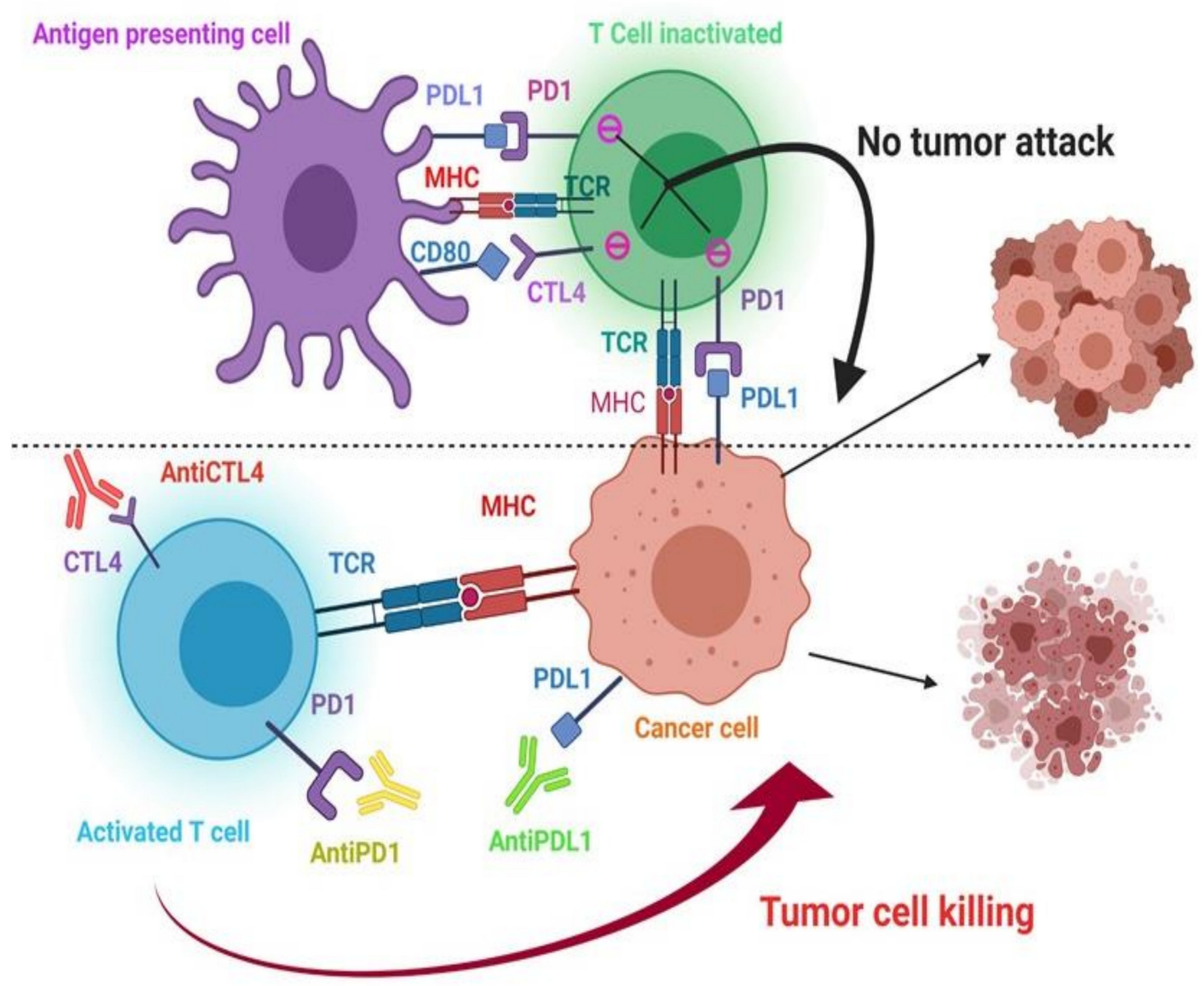

Figure 2. Immune checkpoint pathway PDL1: Programmed Death-Ligand 1; CTL-4: Cytotoxic T Lymphocyte Antigen 4; CD80: Cluster of Differentiation 80; MHC: Major Histocompatibility Complex; TCR: T Cell Receptor; PD1: Programmed Death 1 (Created by Biorender.com, accessed on 1 December 2020).

ICIs enhance Th1 and Th-17 cell responses and the production of cytokines (IL-6 and IL-17) that lead to abnormal T-regulatory (Treg) cell function and humoral immunity [156]. Many autoimmune diseases are related to an altered Treg/Th17 cell axis. Demyelination is the primary underlying mechanism of neuropathy following ICI therapy. Described side effects of ICIs [157] are: myasthenia gravis (anti-MuSK negative) in $2 \%$ of patients, chronic inflammatory demyelinating polyneuropathy (CIDP) (described in 36 patients to date $[136,137])$, sensorimotor polyneuropathy, autoimmune myopathy, Guillain-Barre syndrome (in $0.25 \%$ of patients treated with ICIs [138]) and its sometimes fatal variants [139], overlaps of MG with myositis and/or myocarditis. Other ICI-related neuromuscular complications are GBS (the second most common), Miller Fisher syndrome [140], and acute motor and sensory axonal neuropathy (AMSAN) [141].

\subsection{Vinca Alkaloid-Induced APN}

The pathogenesis of acute inflammatory demyelinating polyradiculoneuropathy in children undergoing intense chemotherapy could be related to secondary immunodepression. Immune system neoplasms can trigger acute inflammatory demyelinating polyradiculoneuropathy as some viral infections do [142]. Cases of GBS have been reported following the onset of vincristine therapy [158]; for example, a patient with acute lymphoblastic leukemia developed a fulminant motor polyradiculoneuropathy resembling an axonal variant of GBS after a few weeks of vincristine therapy [158,159]. 
Guillain-Barré syndrome may be a possible explanation for the severe and unexpected quadriparesis that may occur in patients with acute leukemia or lymphoma treated with vincristine [160].

Differential diagnosis between vinca alkaloid neurotoxicity and acute inflammatory demyelinating polyradiculoneuropathy can be made by examining nerve conduction velocity and performing a lumbar puncture (which points out albumin-cytological dissociation). Patients with Charcot-Marie-Tooth disease can express a severe and acute vincristine-induced neuropathy $[43,143]$.

Fulminant neuropathy with severe motor involvement in association with vincristine therapy has been observed in patients with underlying Charcot-Marie-Tooth disease [161,162].

\subsection{Proteasome Inhibitor Induced APN}

Bortezomib can lead to a severe polyradiculoneuropathy, with an immune-mediated mechanism affecting the function and survival of immune cells such as lymphocytes and dendritic cells. Similarly to immunosuppressive or immunomodulating agents (such as $\mathrm{TNF} \alpha$ antagonists), the damage induced by bortezomib can be related to a T-cell and humoral immune attack against peripheral nerve myelin, vasculitis-induced nerve ischemia, and inhibition of signaling support for axons [144]. There have been reported cases of demyelinating or mixed axonal-demyelinating neuropathy, with prominent motor involvement, albumin-cytological dissociation and lumbar root enhancement on MRI [145].

Chemotherapeutic agents can damage peripheric neuronal structures such as Schwann cells, myelin and axons in two ways: (1) inducing inflammation, and a consequent increase in proinflammatory cytokines and the exposition of self-epitopes; (2) the activation of the immune system against self-antigens leading to an APN. Nevertheless, further studies will clarify the exact pathogenesis and the proportion of patients affected by this chemotherapyinduced APN.

\section{Radiation-Induced Peripheral Neuropathy (RIPN)}

Radiation may cause damage to various tissues, such as the skin, lymph nodes, peripheral vessels, and peripheral nervous system [163]. Among these complications, neurological malfunctions represent a rare but impacting problem on the QoL of long-term cancer survivors that may lead to sensory and motor impairments in the extremities $[164,165]$.

RIPN is usually irreversible and may appear many years after irradiation and its incidence will eventually increase due to the improved survival and longer life expectancy of patients treated when they were children [166].

At present, there is still a lack of important epidemiological studies and we must consider, regardless, RIPN as a rare complication of cancer treatment. RIPN may present with paresthesias, pain, loss of sensation, weakness and atrophy, which may differ depending on the amplitude of irradiated volume, the radio-sensibility of the irradiated tissue and the anatomic region involved [166].

Diagnosis is often difficult to make. In fact, it is difficult to differentiate neoplastic and radiation-induced plexopathy only from clinical features, although is possible to consider severe pain more suggestive of a neoplastic involvement than paresthesias, more likely referable to the radiation-induced lesion. Diagnosis may be guided by clues such as cutaneous and subcutaneous atrophy, radiotherapy tattoo marks, and combining extraneurological signs (sternoclavicular osteoradionecrosis, radiation-induced cardiopathy, enteritis, or multiple basal cell skin carcinoma) [166]. Due to the lack of symptom specificity, diagnosis is based on neurological expertise, electrophysiological tests, MRI, PET scans and collaboration with the radiotherapist to determine the irradiation volume and site [166]. RIPN is currently a rare and mostly delayed complication of radiotherapy and the impact on the lives of long-surviving patients being treated for pediatric cancer is not yet well established. Clinicians need to be aware of the characteristics with which RIPN can manifest, to properly address differential diagnosis and to accurately manage symptoms. 


\subsection{Pathophysiology of RIPN}

The exact pathophysiology underlying RIPN is not yet fully understood. Direct effects of radiations on Schwann cells and microvessels, causing demyelination and ischemia, seem to play an essential role in the alterations of the nerves' environment, in the triggering of fibrosis and consequently in the onset of neuropathy [163,166]. Radiation-induced fibrosis is a dynamic process that involves fibroblast proliferation, extracellular matrix deposition, transforming growth factor $\$ 1$, connective tissue growth factor, and oxygen free radicals, varying from inflammation to sclerosis over several years, resulting in nerve compression in addition to direct axonal damage [166]. Histologic studies include in the pathophysiologic mechanisms, in addition to classical fibrosis, the formation of multiple nerve root cavernomas [167]. Factors influencing the risk and severity of RIPN in cancer survivors are not specific. Anyway, some radiotherapy-related factors have been identified such as a large total dose, large dose per fraction, large number of nerve fibers included in the irradiation field, heterogeneous distribution of high doses, and radiotherapy of previously treated areas [166].

\subsection{Clinical Features}

Brachial plexopathy: Radiation-induced brachial plexopathy rarely occurs as a moderately reversible syndrome, or much more frequently as a delayed and progressive syndrome in patients irradiated to chest or head and neck (lymphoma, Hodgkin's lymphomas, thoracic and apical lung masses, etc.) $[167,168]$. Neurologic symptoms could appear from a few months up to more than 10 years later after radiotherapy (peak 2-4 years) [169]. There is an approximate correlation between the risk of delayed brachial plexopathy and the total radiation dose, establishing $56 \mathrm{~Gy}$ as the "threshold dose" [170]. The clinical onset of brachial plexopathy is often insidious, manifesting with paresthesia or dysesthesia, which may evolve into hypoesthesia and anesthesia, rather than with pain- and progressive motor weakness in a C6-T1 distribution, which is sometimes associated with fasciculations and amyotrophy [166]. Additionally the severity is variable, resulting in some cases of paralysis of the upper limb. This disorder may be accompanied by lymphoedema, which is generally due to high-dose radiotherapy or combined node exeresis and may cause an enhancement of the plexus compression [166].

Lumbosacral plexopathy: Post-radiation damage to the lumbosacral plexus most commonly occurs after the treatment of pelvic and testicular tumors, or tumors that involve para-aortic lymph nodes [171-173]. A mild and reversible plexopathy may occur a few months after radiotherapy, while a severe and delayed neuropathy may occur after 5 years of latency, presenting with slowly, progressive, asymmetric and bilateral leg weakness [173]. Additionally, in radiation-induced lumbosacral plexopathy, pain is usually absent [173].

Radiation-induced spinal cord injury occurs after extraneural paraspinal primary tumor irradiation, and less often in patients treated for spinal gliomas or who have undergone craniospinal irradiation. The most common form of radiation myelopathy is transient, usually occurring about 6 months after treatment, and manifesting with paresthesias and Lhermitte's syndrosme. There is also a generally delayed form of severe radiation myelopathy (1-2 years after radiation therapy) that presents with numbness or dysesthesia of the legs, possibly progressing to weakness and sphincter dysfunction, usually without pain. In most patients, the neurological deficit progresses, leading in $50 \%$ of patients to paraplegia or quadriplegia, with difficult recovery [174].

\subsection{Treatment of RIPN}

Treatment options for patients with RIPN are limited and currently not satisfactory. The principal concern is to treat symptoms, as there is currently no curative strategy. The best approach always includes prevention in respect of radiotherapy dose limits. If a pain component is present, treatment with analgesics, benzodiazepines, tricyclic antidepressants and antiepileptics is generally effective; benzodiazepines and quinine may be used for paraesthesias and cramps, while carbamazepine may reduce nerve hyperexcitability [166]. 
Vitamins B1-B6 are often proposed for their neuroprotective effects, but there is no evidence of their efficacy in RIPN [166]. Physical therapy helps maintain function and prevent joint complications, which can exacerbate pain and restrict movement [166]. Due to vascular damage, heparin and warfarin have been used with the intent of retarding the progression of radiation fibrosis, with neurologic improvement described in a few patients [175]. Surgical neurolysis is an additional treatment option that rarely relieves motor or sensory impairments, and it is unclear whether it can slow the progression of deficits. Surgical methods have not proven useful to date in the management of RIPN [166,174]. Evidence for the benefit of hyperbaric oxygen on radiation-induced fibrosis is not clear, and the literature is populated by studies that have reported undefined complications and fail to demonstrate neurologic benefit $[166,174,176]$. The removal of triggers that can exacerbate it helps control the progression of RIPN, such as controlling high blood pressure, diabetes and alcohol abuse. Controlling acute inflammation with corticosteroids may also be useful in containing the extent and intensity of fibrosis, but there is a lack of objectivity regarding their ability to reduce nerve fiber fibrosis [166]. A combination of pentoxifyllin and tocopherol has been proved to be effective in reducing radiation-induced fibrosis [177], inducing symptom stabilization more than neurologic improvement [178]. A combination of pentoxifyllin and tocopherol with clodronate (Pentoclo) showed an improved outcome [179].

RIPN is currently a rare and mostly delayed complication of radiotherapy, the impact of which on the lives of long-surviving patients treated for pediatric cancer is not yet well established. Clinicians need to be aware of the characteristics with which radiationinduced neuropathy can manifest in order to properly address differential diagnosis and to accurately manage symptoms. It is auspicious that in the future more studies with large cohorts focused on ex-pediatric patients will be conducted, so that future efforts will be directed toward modulating the use of radiation therapy, ensuring the best efficacy and best QoL.

\section{Enteric Nervous System and Chemotherapy-Induced Enteric Neurotoxicity}

The enteric nervous system (ENS) comprises an intricate network of neurons distributed in two major ganglionated plexi (myenteric and submucosal) and other cells including interstitial cells of Cajal and enteric glial cells distributed along the gastrointestinal (GI) tract. The myenteric plexus is located between the circular and longitudinal layer of the muscularis externa and provides motor innervation to muscle layers of the GI tract, whereas the submucosal plexus innervates the epithelium and submucosal vessels controlling vascular tone and water and electrolyte balance [180].

Changes in the density and morphology of enteric neurons, so called enteric neuropathy, have been implicated in a wide range of GI disorders including achalasia, Hirschsprung's disease, slow-transit constipation and chronic intestinal pseudo-obstruction [181,182]. Enteric neuropathies are emerging as key players in chemotherapy-induced GI dysfunction [183]. Significant enteric neuronal loss and functional and structural changes in myenteric neurons correlated with effects on GI motility and have been reported in animal models [184-186] and colonic samples of adult patients receiving chemotherapy [187]. In a mouse model, cisplatin administration significantly reduces the number of myenteric neurons in the gastric fundus and colon and is able to alter the proportion of a certain subpopulation of neurons in the myenteric plexus increasing the expression of neuronal nitric oxide synthase-immunoreactive (nNOS-IR) neurons and reducing the expression of calcitonin genre-related-immunoreactive neurons. These neuronal changes correlate with reduced upper GI and colonic transit $[185,186]$. Similarly, oxaliplatin (OXL) administration induces neuronal loss in the myenteric and submucosal plexus of the small and large bowel, causing a significant increase in the proportion of nNOS-IR colonic neurons, which is correlated with a reduction in muscle thickness and colonic contractility [187,188]. Interestingly, it has been found that co-treatment of OXL with BGP-15, a cytoprotectant, and an antioxidant, resveratrol, improved neuronal survival and related GI dysfunction, emphasizing 
the ENS as a promising therapeutic target for the prevention of chemotherapy-induced enteric neuropathy $[189,190]$.

In a mous model, 5-Fluorouracil (5-FU) administration is associated with damage to the epithelial brush border and the loss of colonic crypts and goblet cells. McQuade et al. demonstrated that this acute inflammation was associated with the loss of excitatory and inhibitory neurons in the myenteric plexus, and that these changes were correlated with delayed GI transit and colonic dysmotility [191]. Interestingly, the inhibition of enteric gliosis by s100 $\beta$ blocker, pentamidine, prevented 5-FU-induced intestinal inflammation, oxidative stress, neuronal loss, enteric glia activation, and histological changes in mice [186]. In a mouse model treatment with irinotecan significantly reduces the number of myenteric neurons and increases the proportion of choline acetyltransferase (ChAT)-IR neurons and vesicular acetylcholine transporter (vAChT)-IR fibers in the myenteric plexus of the distal colon. These ENS changes correlated with increased GI transit time and diarrhea [192]. A recent study further demonstrated that following vincristine administration in rats, the proportion of nNOS-IR myenteric neurons in the distal colon was significantly increased [193].

Although no data are available in pediatric patients, during the first stages of life the intestine is outlined by an immature immune system, an altered intestinal permeability and a premature microbiota development, being more liable to different type of injuries [194]. Of note, chemotherapy-induced mucositis during an early, vulnerable period of neural plasticity could lead to long-lasting hypersensitivity that outlasts the acute inflammation [195].

\section{Critical Illness Polyneuropathy in Pediatric Cancer}

Critical illness polyneuropathy (CIP) is a rare entity in pediatric age that was reported for the first time by Bolton et al. in 1984. It represents a serious adverse event that may complicate the course of leukemia or other malignancies in pediatric patients [196]. CIP is a distal motor and sensory axonal polyneuropathy, often with additional myopathic involvement regarding severely ill patients in critical conditions, especially when they are admitted to the pediatric intensive care unit. Pediatric cancer patients have a higher risk of entering PICUs for complications related to therapy and disease, such as tumor lysis syndrome or immunosuppression and infections [197]. Risk factors of childhood CIP have not been understood; however, sepsis, asthma and transplantation may be responsible [198]. The etiology is attributable to the accumulation of neurotoxic factors with reduced microvascular circulation caused by endoneural hypoxia with distal axonopathy of both sensory and motor nerves as a result of its impairment of axonal transport and action potential generation $[196,197,199]$. In the case of systemic inflammatory response syndrome, edema of nerves is caused by interactions of inflammatory cytokines and adhesion molecules that cause microvascular dilatation with vascular permeability [196].

Electrophysiology features are a loss of both compound muscle and sensory nerve action potentials [197]. Pediatric CIP remains poorly described, and histopathological features have been reported with severe axonal neuropathy, but demyelination has not been described [200].

The timing of the presentation of CIP is not clearly correlated with specific leukemia therapy $[197,200]$. Hirabayashi et al. [201] reported a particular CIP in a 15-year-oldboy affected by acute lymphoblastic leukemia with a Bacillus cereus sepsis in the postchemotherapeutic neutropenia phase. The authors postulated that neutrophils have a functional capacity as powerful mediators of tissue inflammation. The mortality of CIP in children seems to be less than in adults, but effective treatment of CIP at present is only rehabilitation therapy; there is no preventive therapy for CIP, but intensive insulin therapy and the maintenance of normoglycemia have been reported to reduce the incidence of CIP by $44 \%$ and overall mortality during intensive care by more than $40 \%$ [193]. The long-term outcome of pediatric CIP is unclear but has been reported with a $50 \%$ chance of complete recovery [202]. 


\section{Conclusions}

Peripheral neuropathy is a well described complication in pediatric cancer.

Presently, peripheral neuropathy is a challenging complication in chemotherapytreated patients who may present with other possible causes of peripheral nerve damage when chemotherapy is administered and already shows paresthesia or dysesthesia before the start of treatment. Depending on the type of nerve damage, motor, sensory, or autonomic symptoms can be present. Neuropathies directly resulting from lymphomas are quite rare, as well as paraneoplastic neuropathy and cancer-associated vasculitic neuropathies. Complications of radiotherapy, including plexopathies, lower motor neuron syndrome, cranial nerve dysfunction and exceptional peripheral nerve tumors, have now been well reported. Oncologists are generally well aware of the toxicity of therapies, but the side effects of newer drugs are always to be feared and discovered, as illustrated by the complications reported with bortezomib. As chemotherapeutic agents have been correlated with the activation of immune systems (CIPN), an abnormal response can lead to APN. This happens when immunologic tolerance to myelin or axonal antigens is lost. APN includes acute/subacute neuropathy such as GBS and variants or chronic neuropathies such as CIDP or MMN. The incidence of APN as a chemotherapeutic side effect depends on the type of drug administered. Despite different mechanisms of immunity dysregulation and types of chemotherapeutic agents, APN typically presents with demyelination features with the exception of the few axonal variants of polyradiculoneuropathies.

Less frequent but more severe may be RIPN because radiation may cause irreversible PNS damage and also may appear years after irradiation, and its incidence will eventually increase due to the improved survival and longer life expectancy of patients treated when they were children. The severity of radiation is probably directly correlated to direct nerve damage, reactive fibrosis and the formation of multiple nerve root cavernomas.

The recommendation to screen children receiving anticancer therapy for peripheral neuropathy is essential in order to establish a correct treatment strategy. It is also important to point out that neuropathy can persist even after the end of anticancer therapy despite proper management. There is a need for further studies to improve knowledge of how inherited genetic variants contribute to the susceptibility and severity of peripheral neuropathy secondary to cancer therapy. In addition, better surveillance strategies are needed, particularly for young children and those with CNS tumors. Finally, more research is needed on pharmacological agents for the prevention or treatment of the condition, as well as rehabilitation interventions in order to give patients appropriate and effective anticancer therapy and ensure the alleviation of toxicity associated with pain and functional deterioration.

Author Contributions: Conceptualization and validation, S.P., A.M., P.P. and U.R.; writing-first draft preparation, A.B., M.S., M.V. (Margherita Velardi), A.M.C., E.F., F.B., I.A. and G.D.N.; writingreviewing and editing of the paper in the pre-submission step, S.P., A.B., A.M. and U.R.; supervision, L.V., A.C., M.V. (Massimiliano Valeriani), A.R. and P.P. All authors have read and agreed to the published version of the manuscript.

Funding: This research received no external funding.

Acknowledgments: The authors thank Megan Eckley for helping in the English final version.

Conflicts of Interest: The authors declare that they have no potential conflict of interest with respect to the research, authorship, and/or publication of this article.

\section{References}

1. Pike, C.T.; Birnbaum, H.G.; Muehlenbein, C.E.; Pohl, G.M.; Natale, R.B. Healthcare costs and workloss burden of patients with chemotherapy-associated peripheral neuropathy in breast, ovarian, head and neck, and nonsmall cell lung cancer. Chemother. Res. Pract. 2012, 913848. [CrossRef] [PubMed]

2. Starobova, H.; Vetter, I. Pathophysiology of chemotherapy-induced peripheral neuropathy. Front. Mol. Neurosci. 2017, 31, 174. [CrossRef] 
3. Kandula, T.; Park, S.B.; Cohn, R.J.; Krishnan, A.V.; Farrar, M.A. Pediatric chemotherapy induced peripheral neuropathy: A systematic review of current knowledge. Cancer Treat. Rev. 2016, 50, 118-128. [CrossRef] [PubMed]

4. Bjornard, K.L.; Gilchrist, L.S.; Inaba, H.; Diouf, B.; Hockenberry, M.J.; Kadan-Lottick, N.S.; Bowers, D.C.; Dolan, M.E.; Ullrich, N.J.; Evans, W.E.; et al. Peripheral neuropathy in children and adolescents treated for cancer. Lancet Child. Adolesc. Health. 2018, 10, 744-754. [CrossRef]

5. $\quad$ Park, S.B.; Goldstein, D.; Krishnan, A.V.; Lin, C.S.; Friedlander, M.L.; Cassidy, J.; Koltzenburg, M.; Kiernan, M.C. Chemotherapyinduced peripheral neurotoxicity: A critical analysis. CA Cancer J. Clin. 2013, 63, 419-437. [CrossRef] [PubMed]

6. Kandula, T.; Farrar, M.A.; Cohn, R.J.; Mizrahi, D.; Carey, K.; Johnston, K.; Kiernan, M.C.; Krishnan, A.V.; Park, S.B. Chemotherapyinduced peripheral neuropathy in long-term survivors of childhood cancer: Clinical, neurophysiological, functional, and patient-reported outcomes. JAMA Neurol. 2018, 75, 980-988. [CrossRef] [PubMed]

7. McHaney, V.A.; Thibadoux, G.; Hayes, F.A.; Green, A.A. Hearing loss in children receiving cisplatin chemotherapy. J. Pediatr. 1983, 102, 314-317. [CrossRef]

8. Mollman, J.E. Cisplatin neurotoxicity. N. Engl. J. Med. 1990, 322, 126-127. [CrossRef]

9. Tuxen, M.K.; Hansen, S.W. Neurotoxicity secondary to antineoplastic drugs. Cancer Treat. Rev. 1994, 20, 191-214. [CrossRef]

10. Cvitkovic, E. Cumulative toxicities from cisplatin therapy and current cytoprotective measures. Cancer Treat. Rev. 1998, 24, 265-281. [CrossRef]

11. Geisler, S.; Doan, R.A.; Strickland, A.; Huang, X.; Milbrandt, J.; DiAntonio, A. Prevention of vincristine-induced peripheral neuropathy by genetic deletion of SARM1 in mice. Brain 2016, 139, 3092-3108. [CrossRef]

12. Sittl, R.; Lampert, A.; Huth, T.; Schuy, E.T.; Link, A.S.; Fleckenstein, J.; Alzheimer, C.; Grafe, P.; Carr, R.W. Anticancer drug oxaliplatin induces acute cooling-aggravated neuropathy via sodium channel subtype $\mathrm{Na}(\mathrm{V}) 1.6$-resurgent and persistent current. Proc. Natl. Acad. Sci. USA 2012, 109, 6704-6709. [CrossRef] [PubMed]

13. Mora, E.; Smith, E.M.; Donohoe, C.; Hertz, D.L. Vincristine-induced peripheral neuropathy in pediatric cancer patients. Am. J. Cancer Res. 2016, 6, 2416-2430. [PubMed]

14. Lavoie Smith, E.M.; Li, L.; Chiang, C.; Thomas, K.; Hutchinson, R.J.; Wells, E.M.; Ho, R.H.; Skiles, J.; Chakraborty, A.; Bridges, C.M.; et al. Patterns and severity of vincristine-induced peripheral neuropathy in children with acute lymphoblastic leukemia. $J$. Peripher. Nerv. Syst. 2015, 20,37-46. [CrossRef]

15. Egbelakin, A.; Ferguson, M.J.; MacGill, E.A.; Lehmann, A.S.; Topletz, A.R.; Quinney, S.K.; Li, L.; McCammack, K.C.; Hall, S.D.; Renbarger, J.L. Increased risk of vincristine neurotoxicity associated with low CYP3A5 expression genotype in children with acute lymphoblastic leukemia. Pediatr. Blood Cancer 2011, 56, 361-367. [CrossRef] [PubMed]

16. Purser, M.J.; Johnston, D.L.; McMillan, H.J. Chemotherapy-induced peripheral neuropathy among Paediatric Oncology Patients. Can. J. Neurol. Sci. 2014, 41, 442-447. [CrossRef]

17. Courtemanche, H.; Magot, A.; Ollivier, Y.; Rialland, F.; Leclair-Visonneau, L.; Fayet, G.; Camdessanché, J.P.; Péréon, Y. Vincristineinduced neuropathy: Atypical electrophysiological patterns in children. Muscle Nerve 2015, 52, 981-985. [CrossRef]

18. Bay, A.; Yilmaz, C.; Yilmaz, N.; Oner, A.F. Vincristine induced cranial polyneuropathy. Indian J. Pediatr. 2006, 73, 531-533. [CrossRef] [PubMed]

19. Lassaletta, A.; Scheinemann, K.; Zelcer, S.M.; Hukin, J.; Wilson, B.A.; Jabado, N.; Carret, A.S.; Lafay-Cousin, L.; Larouche, V.; Hawkins, C.E.; et al. Phase II weekly vinblastine for chemotherapy-naïve children with progressive low-grade glioma: A canadian pediatric brain tumor consortium study. J. Clin. Oncol. 2016, 34, 3537-3543. [CrossRef]

20. Cavaletti, G.; Gilardini, A.; Canta, A.; Rigamonti, L.; Rodriguez-Menendez, V.; Ceresa, C.; Marmiroli, P.; Bossi, M.; Oggioni, N.; D'Incalci, M.; et al. Bortezomib-induced peripheral neurotoxicity: A neurophysiological and pathological study in the rat. Exp. Neurol. 2007, 204, 317-325. [CrossRef]

21. Schiff, D.; Wen, P.Y.; van den Bent, M.J. Neurological adverse effects caused by cytotoxic and targeted therapies. Nat. Rev. Clin. Oncol. 2009, 6, 596-603. [CrossRef]

22. Dawkins, J.L.; Hulme, D.J.; Brahmbhatt, S.B.; Auer-Grumbach, M.; Nicholson, G.A. Mutations in SPTLC1, encoding serine palmitoyltransferase, long chain base subunit-1, cause hereditary sensory neuropathy type I. Nat. Genet. 2001, $27,309-312$. [CrossRef]

23. Dunsmore, K.P.; Winter, S.S.; Devidas, M.; Wood, B.L.; Esiashvili, N.; Chen, Z.; Eisenberg, N.; Briegel, N.; Hayashi, R.J.; Gastier Foster, J.M.; et al. Children's Oncology Group AALL0434: A Phase III Randomized Clinical Trial Testing Nelarabine in Newly Diagnosed T-Cell Acute Lymphoblastic Leukemia. J. Clin. Oncol. 2020, 38, 3282-3293. [CrossRef]

24. DeAngelo, D.J. Nelarabine for the treatment of patients with relapsed or refractory T-cell acute lymphoblastic leukemia or lymphoblastic lymphoma. Hematol. Oncol. Clin. N. Am. 2009, 23, 1121-1135, vii-viii. [CrossRef] [PubMed]

25. Ewins, K.; Malone, A.; Phelan, E.; Webb, D.; McHugh, J.C.; Smith, O. Nelarabine-induced peripheral and central neurotoxicity: Can sequential MRI brain imaging help to define its natural history? Br. J. Haematol. 2017, 294-297. [CrossRef] [PubMed]

26. Stone, J.B.; DeAngelis, L.M. Cancer-treatment-induced neurotoxicity-Focus on newer treatments. Nat. Rev. Clin. Oncol. 2016, 13, 92-105. [CrossRef] [PubMed]

27. Langholz, B.; Skolnik, J.M.; Barrett, J.S.; Renbarger, J.; Seibel, N.L.; Zajicek, A.; Arndt, C.A. Dactinomycin and vincristine toxicity in the treatment of childhood cancer: A retrospective study from the Children's Oncology Group. Pediatr. Blood Cancer 2011, 57, 252-257. [CrossRef] 
28. Gilchrist, L.S.; Tanner, L.R.; Ness, K.K. Short-term recovery of chemotherapy-induced peripheral neuropathy after treatment for pediatric non-CNS cancer. Pediatr. Blood Cancer 2017, 64, 180-187. [CrossRef]

29. Moore, R.J.; Groninger, H. Chemotherapy-induced peripheral neuropathy in pediatric cancer patients. Cureus 2013, 5, e124. [CrossRef]

30. Gilchrist, L. Chemotherapy-induced peripheral neuropathy in pediatric cancer patients. Semin. Pediatr. Neurol. 2012, 19, 9-17. [CrossRef]

31. Ness, K.K.; Hudson, M.M.; Pui, C.H.; Green, D.M.; Krull, K.R.; Huang, T.T.; Robison, L.L.; Morris, E.B. Neuromuscular impairments in adult survivors of childhood acute lymphoblastic leukemia: Associations with physical performance and chemotherapy doses. Cancer 2012, 118, 828-838. [CrossRef]

32. Ness, K.K.; Jones, K.E.; Smith, W.A.; Spunt, S.L.; Wilson, C.L.; Armstrong, G.T.; Srivastava, D.K.; Robison, L.L.; Hudson, M.M.; Gurney, J.G. Chemotherapy-related neuropathic symptoms and functional impairment in adult survivors of extracranial solid tumors of childhood: Results from the St. Jude Lifetime Cohort Study. Arch. Phys. Med. Rehabil. 2013, 94, 1451-1457. [CrossRef]

33. Varedi, M.; McKenna, R.; Lamberg, E.M. Balance in children with acute lymphoblastic leukemia. Pediatr. Int. 2017, 59, 293-302. [CrossRef]

34. Tay, C.G.; Lee, V.W.M.; Ong, L.C.; Goh, K.J.; Ariffin, H.; Fong, C.Y. Vincristine-induced peripheral neuropathy in survivors of childhood acute lymphoblastic leukaemia. Pediatr. Blood Cancer 2017, 64. [CrossRef] [PubMed]

35. Jordan, M.A.; Wilson, L. Microtubules as a target for anticancer drugs. Nat. Rev. Cancer 2004, 4, 253-265. [CrossRef] [PubMed]

36. Cavaletti, G.; Alberti, P.; Argyriou, A.A.; Lustberg, M.; Staf, N.P.; Tamburin, S. Chemotherapy-induced peripheral neurotoxicity: A multifaceted, still unsolved issue. J. Peripher. Nerv. Syst. 2019, 24, S6-S12. [CrossRef] [PubMed]

37. Moriyama, B.; Henning, S.A.; Leung, J.; Falade-Nwulia, O.; Jarosinski, P.; Penzak, S.R.; Walsh, T.J. Adverse interactions between antifungal azoles and vincristine: Review and analysis of cases. Mycoses 2012, 55, 290-297. [CrossRef]

38. Teusink, A.C.; Ragucci, D.; Shatat, I.F.; Kalpatthi, R. Potentiation of vincristine toxicity with concomitant fluconazole prophylaxis in children with acute lymphoblastic leukemia. Pediatr. Hematol. Oncol. 2012, 29, 62-67. [CrossRef]

39. Bhushan, B.; Bhargava, A.; Kasundra, G.M.; Shubhakaran, K.; Sood, I. Guillain-Barre syndrome in acute lymphoblastic leukemia: Causal or coincidental. J. Pediatr. Neurosci. 2015, 10, 64-66. [CrossRef]

40. Beutler, A.S.; Kulkarni, A.A.; Kanwar, R.; Klein, C.J.; Therneau, T.M.; Qin, R.; Banck, M.S.; Boora, G.K.; Ruddy, K.J.; Wu, Y.; et al. Sequencing of Charcot-Marie-Tooth disease genes in a toxic polyneuropathy. Ann. Neurol. 2014, 76, 727-737. [CrossRef]

41. van de Velde, M.E.; Kaspers, G.L.; Abbink, F.C.H.; Wilhelm, A.J.; Ket, J.C.F.; van den Berg, M.H. Vincristine-induced peripheral neuropathy in children with cancer: A systematic review. Crit. Rev. Oncol. Hematol. 2017, 114, 114-130. [CrossRef]

42. Kuehl, P.; Zhang, J.; Lin, Y.; Lamba, J.; Assem, M.; Schuetz, J.; Watkins, P.B.; Daly, A.; Wrighton, S.A.; Hall, S.D.; et al. Sequence diversity in CYP3A promoters and characterization of the genetic basis of polymorphic CYP3A5 expression. Nat. Genet. 2001, 27, 383-391. [CrossRef] [PubMed]

43. Brigo, F.; Balter, R.; Marradi, P.; Ferlisi, M.; Zaccaron, A.; Fiaschi, A.; Frasson, E.; Bertolasi, L. Vincristine-related neuropathy versus acute inflammatory demyelinating polyradiculoneuropathy in children with acute lymphoblastic leukemia. J. Child. Neurol. 2012, 27, 867-874. [CrossRef]

44. Aghajan, Y.; Yoon, J.M.; Crawford, J.R. Severe vincristine-induced polyneuropathy in a teenager with anaplastic medulloblastoma and undiagnosed Charcot-Marie-Tooth disease. BMJ Case Rep. 2017, 2017, bcr2016218981. [CrossRef] [PubMed]

45. Chauvenet, A.R.; Shashi, V.; Selsky, C.; Morgan, E.; Kurtzberg, J.; Bell, B. Pediatric Oncology Group Study. Vincristine-induced neuropathy as the initial presentation of charcot-marie-tooth disease in acute lymphoblastic leukemia: A Pediatric Oncology Group study. J. Pediatr. Hematol. Oncol. 2003, 25, 316-320. [CrossRef] [PubMed]

46. Kandula, T.; Farrar, M.A.; Kiernan, M.C.; Krishnan, A.V.; Goldstein, D.; Horvath, L.; Grimison, P.; Boyle, F.; Baron-Hay, S.; Park, S.B. Neurophysiological and clinical outcomes in chemotherapy-induced neuropathy in cancer. Clin. Neurophysiol. 2017, 128, 1166-1175. [CrossRef]

47. Li, Y.; Womer, R.B.; Silber, J.H. Predicting cisplatin ototoxicity in children: The influence of age and the cumulative dose. Eur. J. Cancer 2004, 40, 2445-2451. [CrossRef]

48. Paulino, A.C.; Lobo, M.; The, B.S.; Okcu, M.F.; South, M.; Butler, E.B.; Su, J.; Chintagumpala, M. Ototoxicity after intensitymodulated radiation therapy and cisplatin-based chemotherapy in children with medulloblastoma. Int. J. Radiat. Oncol. Biol. Phys. 2010, 78, 1445-1450. [CrossRef]

49. Freyer, D.R.; Brock, P.R.; Chang, K.W.; Dupuis, L.L.; Epelman, S.; Knight, K.; Mills, D.; Phillips, R.; Potter, E.; Risby, D.; et al. Prevention of cisplatin-induced ototoxicity in children and adolescents with cancer: A clinical practice guideline. Lancet Child. Adolesc. Health 2020, 4, 141-150. [CrossRef]

50. Podratz, J.L.; Knight, A.M.; Ta, L.E.; Staff, N.P.; Gass, J.M.; Genelin, K.; Schlattau, A.; Lathroum, L.; Windebank, A.J. Cisplatin induced mitochondrial DNA damage in dorsal root ganglion neurons. Neurobiol. Dis. 2011, 41, 661-668. [CrossRef]

51. Canta, A.; Pozzi, E.; Carozzi, V.A. Mitochondrial dysfunction in chemotherapy-induced peripheral neuropathy (CIPN). Toxics 2015, 3, 198-223. [CrossRef] [PubMed]

52. Carozzi, V.A.; Canta, A.; Chiorazzi, A. Chemotherapy-induced peripheral neuropathy: What do we know about mechanisms? Neurosci. Lett. 2015, 596, 90-107. [CrossRef]

53. Wang, J.T.; Medress, Z.A.; Barres, B.A. Axon degeneration: Molecular mechanisms of a self-destruction pathway. J. Cell Biol. 2012, 196, 7-18. [CrossRef] 
54. Jin, X.; Gereau, R.W., 4th. Acute p38-mediated modulation of tetrodotoxin-resistant sodium channels in mouse sensory neurons by tumor necrosis factor-alpha. J. Neurosci. 2006, 26, 246-255. [CrossRef] [PubMed]

55. van der Vijgh, W.J. Clinical pharmacokinetics of carboplatin. Clin. Pharmacol. 1991, 21, 242-261. [CrossRef]

56. Loss, J.F.; Santos, P.P.; Leone, L.D.; Brunetto, A.L. Outcome of pediatric recurrent and refractory malignant solid tumors following ifosfamide/carboplatin/etoposide (ICE): A phase II study in a pediatric oncology centre in Brazil. Pediatr. Blood Cancer 2004, 42, 139-144. [CrossRef]

57. Staff, N.P.; Podratz, J.L.; Grassner, L.; Bader, M.; Paz, J.; Knight, A.M.; Loprinzi, C.L.; Trushina, E.; Windebank, A.J. Bortezomib alters microtubule polymerization and axonal transport in rat dorsal root ganglion neurons. Neurotoxicology 2013, 39, 124-131. [CrossRef]

58. Sandler, S.G.; Tobin, W.; Henderson, E.S. Vincristine-induced neuropathy. A clinical study of fifty leukemic patients. Neurology 1969, 19, 367-374. [CrossRef] [PubMed]

59. Lobert, S.; Vulevic, B.; Correia, J.J. Interaction of vinca alkaloids with tubulin: A comparison of vinblastine, vincristine, and vinorelbine. Biochemistry 1996, 35, 6806-6814. [CrossRef]

60. Chan, S.Y.; Worth, R.; Ochs, S. Block of axoplasmic transport in vitro by vinca alkaloids. J. Neurobiol. 1980, 11, 251-264. [CrossRef] [PubMed]

61. Hudson, M.M.; Neglia, J.P.; Woods, W.G.; Sandlund, J.T.; Pui, C.H.; Kun, L.E.; Robison, L.L.; Green, D.M. Lessons from the past: Opportunities to improve childhood cancer survivor care through outcomes investigations of historical therapeutic approaches for pediatric hematological malignancies. Pediatr. Blood Cancer 2012, 58, 334-343. [CrossRef] [PubMed]

62. Green, D.M.; Kun, L.E.; Matthay, K.K.; Meadows, A.T.; Meyer, W.H.; Meyers, P.A.; Spunt, S.L.; Robison, L.L.; Hudson, M.M. Relevance of historical therapeutic approaches to the contemporary treatment of pediatric solid tumors. Pediatr. Blood Cancer 2013, 60, 1083-1094. [CrossRef]

63. Yildiz, F.G.; Temucin, Ç.M. Vincristine-induced neurotoxicity: Electrophysiological features in children. Neurol. Res. 2016, 38, 124-129. [CrossRef]

64. Kavcic, M.; Koritnik, B.; Krzan, M.; Velikonja, O.; Prelog, T.; Stefanovic, M.; Debeljak, M.; Jazbec, J. Electrophysiological studies to detect peripheral neuropathy in children treated with vincristine. J. Pediatr. Hematol. Oncol. 2017, 39, 266-271. [CrossRef]

65. Harila-Saari, A.H.; Vainionpää, L.K.; Kovala, T.T.; Tolonen, E.U.; Lanning, B.M. Nerve lesions after therapy for childhood acute lymphoblastic leukemia. Cancer 1998, 82, 200-207. [CrossRef]

66. Lehtinen, S.S.; Huuskonen, U.E.; Harila-Saari, A.H.; Tolonen, U.; Vainionpää, L.K.; Lanning, B.M. Motor nervous system impairment persists in long-term survivors of childhood acute lymphoblastic leukemia. Cancer 2002, 94, 2466-2473. [CrossRef]

67. Jain, P.; Gulati, S.; Seth, R.; Bakhshi, S.; Toteja, G.S.; Pandey, R.M. Vincristine-induced neuropathy in childhood ALL (acute lymphoblastic leukemia) survivors: Prevalence and electrophysiological characteristics. J. Child. Neurol. 2014, $29,932-937$. [CrossRef]

68. Ramchandren, S.; Leonard, M.; Mody, R.J.; Donohue, J.E.; Moyer, J.; Hutchinson, R.; Gurney, J.G. Peripheral neuropathy in survivors of childhood acute lymphoblastic leukemia. J. Peripher. Nerv. Syst. 2009, 14, 184-189. [CrossRef]

69. Hayashi, R.J.; Blaney, S.; Sullivan, J.; Weitman, S.; Vietti, T.; Bernstein, M.L. Pediatric Oncology Group Study. Phase 1 study of Paclitaxel administered twice weekly to children with refractory solid tumors: A pediatric oncology group study. J. Pediatr. Hematol. Oncol. 2003, 25, 539-542. [CrossRef]

70. Shemesh, O.A.; Spira, M.E. Paclitaxel induces axonal microtubules polar reconfiguration and impaired organelle transport: Implications for the pathogenesis of paclitaxel-induced polyneuropathy. Acta Neuropathol. 2010, 119, 235-248. [CrossRef] [PubMed]

71. LaPointe, N.E.; Morfini, G.; Brady, S.T.; Feinstein, S.C.; Wilson, L.; Jordan, M.A. Effects of eribulin, vincristine, paclitaxel and ixabepilone on fast axonal transport and kinesin-1 driven microtubule gliding: Implications for chemotherapy-induced peripheral neuropathy. Neurotoxicology 2013, 37, 231-239. [CrossRef] [PubMed]

72. Bober, B.G.; Shah, S.B. Paclitaxel alters sensory nerve biomechanical properties. J. Biomech. 2015, 48, 3559-3567. [CrossRef]

73. Zheng, H.; Xiao, W.H.; Bennett, G.J. Mitotoxicity and bortezomib-induced chronic painful peripheral neuropathy. Exp. Neurol. 2012, 238, 225-234. [CrossRef] [PubMed]

74. Messinger, Y.H.; Gaynon, P.S.; Sposto, R.; van der Giessen, J.; Eckroth, E.; Malvar, J.; Bostrom, B.C. Therapeutic Advances in Childhood Leukemia \& Lymphoma (TACL) Consortium. Bortezomib with chemotherapy is highly active in advanced B-precursor acute lymphoblastic leukemia: Therapeutic Advances in Childhood Leukemia \& Lymphoma (TACL) Study. Blood 2012, 120, 285-290. [CrossRef]

75. Keller, S.; Seipel, K.; Novak, U.; Mueller, B.U.; Taleghani, B.M.; Leibundgut, K.; Pabst, T. Neurotoxicity of stem cell mobilization chemotherapy with vinorelbine in myeloma patients after bortezomib treatment. Leuk. Res. 2015, 39, 786-792. [CrossRef]

76. Salvemini, D.; Doyle, T.; Kress, M.; Nicol, G. Therapeutic targeting of the ceramide-to- sphingosine 1-phosphate pathway in pain. Trends. Pharmacol. Sci. 2013, 34, 110-118. [CrossRef]

77. Stockstill, K.; Doyle, T.M.; Yan, X.; Chen, Z.; Janes, K.; Little, J.W.; Braden, K.; Lauro, F.; Giancotti, L.A.; Harada, C.M.; et al. Dysregulation of sphingolipid metabolism contributes to bortezomib-induced neuropathic pain. J. Exp. Med. 2018, 215, 1301-1313. [CrossRef]

78. Emery, E.C.; Wood, J.N. Gaining on pain. N. Engl. J. Med. 2018, 379, 485-487. [CrossRef] 
79. Zajączkowska, R.; Kocot-Keepska, M.; Leppert, W.; Wrzosek, A.; Mika, J.; Wordliczek, J. Mechanisms of chemotherapy-induced peripheral neuropathy. Int. J. Mol. Sci. 2019, 20, 1451. [CrossRef] [PubMed]

80. Casafont, I.; Berciano, M.T.; Lafarga, M. Bortezomib induces the formation of nuclear poly(A) RNA granules enriched in Sam68 and PABPN1 in sensory ganglia neurons. Neurotox. Res. 2010, 17, 167-178. [CrossRef] [PubMed]

81. Palanca, A.; Casafont, I.; Berciano, M.T.; Lafarga, M. Proteasome inhibition induces DNA damage and reorganizes nuclear architecture and protein synthesis machinery in sensory ganglion neurons. Cell Mol. Life Sci. 2014, 71, 1961-1975. [CrossRef]

82. Meregalli, C.; Chiorazzi, A.; Carozzi, V.A.; Canta, A.; Sala, B.; Colombo, M.; Oggioni, N.; Ceresa, C.; Foudah, D.; La Russa, F.; et al. Evaluation of tubulin polymerization and chronic inhibition of proteasome as citotoxicity mechanisms in bortezomib-induced peripheral neuropathy. Cell Cycle 2014, 13, 612-621. [CrossRef]

83. Kumar, S.K.; Berdeja, J.G.; Niesvizky, R.; Lonial, S.; Laubach, J.P.; Hamadani, M.; Stewart, A.K.; Hari, P.; Roy, V.; Vescio, R.; et al. Safety and tolerability of ixazomib, an oral proteasome inhibitor, in combination with lenalidomide and dexamethasone in patients with previously untreated multiple myeloma: An open-label phase 1/2 study. Lancet Oncol. 2014, 15, 1503-1512. [CrossRef]

84. Berg, S.L.; Blaney, S.M.; Devidas, M.; Lampkin, T.A.; Murgo, A.; Bernstein, M.; Billett, A.; Kurtzberg, J.; Reaman, G.; Gaynon, P.; et al. Phase II study of nelarabine (compound 506U78) in children and young adults with refractory T-cell malignancies: A report from the Children's Oncology Group. J. Clin. Oncol. 2005, 23, 3376-3382. [CrossRef]

85. Ngo, D.; Patel, S.; Kim, E.J.; Brar, R.; Koontz, M.Z. Nelarabine neurotoxicity with concurrent intrathecal chemotherapy: Case report and review of literature. J. Oncol. Pharm. Pract. 2015, 21, 296-300. [CrossRef]

86. Kurtzberg, J.; Ernst, T.J.; Keating, M.J.; Gandhi, V.; Hodge, J.P.; Kisor, D.F.; Lager, J.J.; Stephens, C.; Levin, J.; Krenitsky, T.; et al. Phase I study of 506U78 administered on a consecutive 5-day schedule in children and adults with refractory hematologic malignancies. J. Clin. Oncol. 2005, 23, 3396-3403. [CrossRef]

87. Papayannidis, C.; Iacobucci, I.; Abbenante, M.C.; Curti, A.; Paolini, S.; Parisi, S.; Baccarani, M.; Martinelli, G. Complete paraplegia after nelarabine treatment in a T-cell acute lymphoblastic leukemia adult patient. Am. J. Hematol. 2010, 85, 608. [CrossRef]

88. Gollard, R.P.; Selco, S. Irreversible myelopathy associated with nelaribine in T-cell acute lymphoblastic leukemia. J. Clin. Oncol. 2013, 3, e327-e331. [CrossRef] [PubMed]

89. Pui, C.H.; Carroll, W.L.; Meshinchi, S.; Arceci, R.J. Biology, risk stratification, and therapy of pediatric acute leukemias: An update. J. Clin. Oncol. 2011, 29, 551-565. [CrossRef] [PubMed]

90. Gilchrist, L.S.; Tanner, L. The pediatric-modified total neuropathy score: A reliable and valid measure of chemotherapy-induced peripheral neuropathy in children with non-CNS cancers. Support. Care Cancer 2013, 2, 847-856. [CrossRef] [PubMed]

91. Gilchrist, L.S.; Marais, L.; Tanner, L. Comparison of two chemotherapy-induced peripheral neuropathy measurement approaches in children. Support. Care Cancer 2014, 22, 359-366. [CrossRef]

92. Lavoie Smith, E.M.; Li, L.; Hutchinson, R.J.; Ho, R.; Burnette, W.B.; Wells, E.; Bridges, C.; Renbarger, J. Measuring vincristineinduced peripheral neuropathy in children with acute lymphoblastic leukemia. Cancer Nurs. 2013, 36, E49-E60. [CrossRef] [PubMed]

93. Cavaletti, G.; Cornblath, D.R.; Merkies, I.S.J.; Postma, T.J.; Rossi, E.; Frigeni, B.; Alberti, P.; Bruna, J.; Velasco, R.; Argyriou, A.A.; et al. The chemotherapy-induced peripheral neuropathy outcome measures standardization study: From consensus to the first validity and reliability findings. Ann. Oncol. 2013, 24, 454-462. [CrossRef] [PubMed]

94. Chen, X.; Haggiagi, A.; Tzatha, E.; DeAngelis, L.M.; Santomasso, B. Electrophysiological findings in immune checkpoint inhibitor-related peripheral neuropathy. Clin. Neurophysiol. 2019, 130, 1440-1445. [CrossRef]

95. Griffith, K.A.; Dorsey, S.G.; Renn, C.L.; Zhu, S.; Johantgen, M.E.; Cornblath, D.R.; Argyriou, A.A.; Cavaletti, G.; Merkies, I.S.; Alberti, P.; et al. Correspondence between neurophysiological and clinical measurements of chemotherapy-induced peripheral neuropathy: Secondary analysis of data from the CI-PeriNomS study. J. Peripher. Nerv. Syst. 2014, 19, 127-135. [CrossRef]

96. Mallik, A.; Weir, I. Nerve conduction studies: Essentials and pitfalls in practice. J. Neurol. Neurosurg. Psychiatry 2005,76 (Suppl. 2), ii23-ii31. [CrossRef]

97. Cavaletti, G.; Frigeni, B.; Lanzani, F.; Mattavelli, L.; Susani, E.; Alberti, P.; Cortinovis, D.; Bidoli, P. Chemotherapy-Induced Peripheral Neurotoxicity assessment: A critical revision of the currently available tools. Eur. J. Cancer 2010, 463, 479-494. [CrossRef]

98. Kokotis, P.; Schmelz, M.; Kostouros, E.; Karandreas, N.; Dimopoulos, M.A. Oxaliplatin-induced neuropathy: A long-term clinical and neurophysiologic follow-up study. Clin. Colorectal. Cancer 2016, 15, e133-e140. [CrossRef]

99. Chen, X.; Stubblefield, M.D.; Custodio, C.M.; Hudis, C.A.; Seidman, A.D.; DeAngelis, L.M. Electrophysiological features of taxane-induced polyneuropathy in patients with breast cancer. J. Clin. Neurophysiol. 2013, 30, 199-203. [CrossRef]

100. Mileshkin, L.; Stark, R.; Day, B.; Seymour, J.F.; Zeldis, J.B.; Prince, H.M. Development of neuropathy in patients with myeloma treated with thalidomide: Patterns of occurrence and the role of electrophysiologic monitoring. J. Clin. Oncol. 2006, 24, 4507-4514. [CrossRef]

101. Fuglsang-Frederiksen, A.; Pugdahl, K. Current status on electrodiagnostic standards and guidelines in neuromuscular disorders. Clin. Neurophysiol. 2011, 122, 440-455. [CrossRef]

102. Hershman, D.L.; Lacchetti, C.; Dworkin, R.H.; Lavoie Smith, E.M.; Bleeker, J.; Cavaletti, G.; Chauhan, C.; Gavin, P.; Lavino, A.; Lustberg, M.B.; et al. Prevention and management of chemotherapy-induced peripheral neuropathy in survivors of adult cancers: American Society of Clinical Oncology clinical practice guideline. J. Clin. Oncol. 2014, 32, 1941-1967. [CrossRef] 
103. Akbayram, S.; Akgun, C.; Doğan, M.; Sayin, R.; Caksen, H.; Oner, A.F. Use of pyridoxine and pyridostigmine in children with vincristine-induced neuropathy. Indian J. Pediatr. 2010, 77, 681-683. [CrossRef] [PubMed]

104. Vondracek, P.; Oslejskova, H.; Kepak, T.; Mazanek, P.; Sterba, J.; Rysava, M.; Gal, P. Efficacy of pregabalin in neuropathic pain in paediatric oncological patients. Eur. J. Paediatr. Neurol. 2009, 13, 332-336. [CrossRef] [PubMed]

105. Anghelescu, D.L.; Faughnan, L.G.; Jeha, S.; Relling, M.V.; Hinds, P.S.; Sandlund, J.T.; Cheng, C.; Pei, D.; Hankins, G.; Pauley, J.L.; et al. Neuropathic pain during treatment for childhood acute lymphoblastic leukemia. Pediatr. Blood Cancer 2011, 57, 1147-1153. [CrossRef] [PubMed]

106. Friedrichsdorf, S.J.; Nugent, A.P. Management of neuropathic pain in children with cancer. Curr. Opin. Support. Palliat. Care 2013, 7, 131-138. [CrossRef] [PubMed]

107. Windsor, R.B.; Tham, S.W.; Adams, T.L.; Anderson, A. The use of opioids for treatment of pediatric neuropathic pain. Clin. J. Pain. 2019, 35, 509-514. [CrossRef]

108. Anghelescu, D.L.; Tesney, J.M. Neuropathic pain in pediatric oncology-A clinical decision algorithm. Paediatr. Drugs 2019, 21, 59-70. [CrossRef]

109. Wacker, K.; Tanner, L.; Ovans, J.; Mason, J.; Gilchrist, L. Improving functional mobility in children and adolescents undergoing treatment for non-central nervous system cancers: A systematic review. PMER 2017, 9, S385-S397. [CrossRef]

110. Gilchrist, L.S.; Tanner, L.R. Short-term recovery of balance control: Association with chemotherapy-induced peripheral neuropathy in pediatric oncology. Pediatr. Phys. Ther. 2018, 30, 119-124. [CrossRef]

111. Tomasello, C.; Pinto, R.M.; Mennini, C.; Conicella, E.; Stoppa, F.; Raucci, U. Scrambler therapy efficacy and safety for neuropathic pain correlated with chemotherapy-induced peripheral neuropathy in adolescents: A preliminary study. Pediatr. Blood Cancer 2018, 65, e27064. [CrossRef] [PubMed]

112. Romano, A.; Capozza, M.A.; Mastrangelo, S.; Maurizi, P.; Triarico, S.; Rolesi, R.; Attinà, G.; Fetoni, A.R.; Ruggiero, A. Assessment and management of platinum-related ototoxicity in children treated for cancer. Cancers 2020, 12, 1266. [CrossRef] [PubMed]

113. Triarico, S.; Romano, A.; Attinà, G.; Capozza, M.A.; Maurizi, P.; Mastrangelo, S.; Ruggiero, A. Vincristine-induced peripheral neuropathy (VIPN) in pediatric tumors: Mechanisms, risk factors, strategies of prevention and treatment. Int. J. Mol. Sci. 2021, 22, 4112. [CrossRef] [PubMed]

114. Freyer, D.R.; Chen, L.; Krailo, M.D.; Knight, K.; Villaluna, D.; Bliss, B.; Pollock, B.H.; Ramdas, J.; Lange, B.; Van Hoff, D.; et al. Effects of sodium thiosulfate versus observation on development of cisplatin-induced hearing loss in children with cancer (ACCL0431): A multicentre, randomised, controlled, open-label, phase 3 trial. Lancet Oncol. 2017, 18, 63-74. [CrossRef]

115. Pachman, D.R.; Barton, D.L.; Watson, J.C.; Loprinzi, C.L. Chemotherapy-induced peripheral neuropathy: Prevention and treatment. Clin. Pharmacol. Ther. 2011, 90,377-387. [CrossRef]

116. Loprinzi, C.L.; Lacchetti, C.; Bleeker, J.; Cavaletti, G.; Chauhan, C.; Hertz, D.L.; Kelley, M.R.; Lavino, A.; Lustberg, M.B.; Paice, J.A.; et al. Prevention and management of chemotherapy-induced peripheral neuropathy in survivors of adult cancers: ASCO Guideline Update. J. Clin. Oncol. 2020, 38, 3325-3348. [CrossRef] [PubMed]

117. Kerckhove, N.; Collin, A.; Condé, S.; Chaleteix, C.; Pezet, D.; Balayssac, D. Long-term effects, pathophysiological mechanisms, and risk factors of chemotherapy-induced peripheral neuropathies: A comprehensive literature review. Front. Pharmacol. 2017, 8, 86. [CrossRef]

118. Mols, F.; van de Poll-Franse, L.V.; Vreugdenhil, G.; Beijers, A.J.; Kieffer, J.M.; Aaronson, N.K.; Husson, O. Reference data of the European organisation for research and treatment of cancer (EORTC) QLQ-CIPN20 questionnaire in the general dutch population. Eur. J. Cancer 2016, 69, 28-38. [CrossRef]

119. Kolb, N.A.; Smith, A.G.; Singleton, J.R.; Beck, S.L.; Stoddard, G.J.; Brown, S.; Mooney, K. The association of chemotherapy-induced peripheral neuropathy symptoms and the risk of falling. JAMA Neurol. 2016, 73, 860-866. [CrossRef]

120. Albers, J.W.; Chaudhry, V.; Cavaletti, G.; Donehower, R.C. Interventions for preventing neuropathy caused by cisplatin and related compounds. Cochrane Database Syst. Rev. 2011, 16, CD005228, Update in: Cochrane Database Syst. Rev. 2014, 3, CD005228. [CrossRef]

121. André, T.; Boni, C.; Mounedji-Boudiaf, L.; Navarro, M.; Tabernero, J.; Hickish, T.; Topham, C.; Zaninelli, M.; Clingan, P.; Bridgewater, J.; et al. Oxaliplatin, fluorouracil, and leucovorin as adjuvant treatment for colon cancer. N. Engl. J. Med. 2004, 350, 2343-2351. [CrossRef] [PubMed]

122. Balayssac, D.; Ferrier, J.; Descoeur, J.; Ling, B.; Pezet, D.; Eschalier, A.; Authier, N. Chemotherapy-induced peripheral neuropathies: From clinical relevance to preclinical evidence. Expert Opin. Drug Saf. 2011, 10, 407-417. [CrossRef]

123. Osmani, K.; Vignes, S.; Aissi, M.; Wade, F.; Milani, P.; Lévy, B.I.; Kubis, N. Taxane-induced peripheral neuropathy has good long-term prognosis: A 1- to 13-year evaluation. J. Neurol. 2012, 259, 1936-1943. [CrossRef] [PubMed]

124. Roché, H.; Yelle, L.; Cognetti, F.; Mauriac, L.; Bunnell, C.; Sparano, J.; Kerbrat, P.; Delord, J.P.; Vahdat, L.; Peck, R.; et al. Phase II clinical trial of ixabepilone (BMS-247550), an epothilone B analog, as first-line therapy in patients with metastatic breast cancer previously treated with anthracycline chemotherapy. J. Clin. Oncol. 2007, 25, 3415-3420. [CrossRef] [PubMed]

125. Perez, E.A.; Lerzo, G.; Pivot, X.; Thomas, E.; Vahdat, L.; Bosserman, L.; Viens, P.; Cai, C.; Mullaney, B.; Peck, R.; et al. Efficacy and safety of ixabepilone (BMS-247550) in a phase II study of patients with advanced breast cancer resistant to an anthracycline, a taxane, and capecitabine. J. Clin. Oncol. 2007, 25, 3407-3414. [CrossRef]

126. Zhang, X.; Chen, W.W.; Huang, W.J. Chemotherapy-induced peripheral neuropathy. Biomed. Rep. 2017, 6, 267-271. [CrossRef] [PubMed] 
127. Brandolini, L.; d'Angelo, M.; Antonosante, A.; Allegretti, M.; Cimini, A. Chemokine signaling in chemotherapy-induced neuropathic pain. Int. J. Mol. Sci. 2019, 20, 2904. [CrossRef]

128. Kany, S.; Vollrath, J.T.; Relja, B. Cytokines in Inflammatory Disease. Int. J. Mol. Sci. 2019, 20, 6008. [CrossRef]

129. Jaggi, A.S.; Singh, N. Mechanisms in cancer-chemotherapeutic drugs-induced peripheral neuropathy. Toxicology 2012, 291, 1-9. [CrossRef]

130. Wang, Z.C.; Li, L.H.; Bian, C.; Yang, L.; Lv, N.; Zhang, Y.Q. Involvement of NF-kB and the CX3CR1 signaling network in mechanical allodynia induced by tetanic sciatic stimulation. Neurosci. Bull. 2018, 34, 64-73. [CrossRef]

131. Fukuda, Y.; Li, Y.; Segal, R.A. A mechanistic understanding of axon degeneration in chemotherapy-induced peripheral neuropathy. Front. Neurosci. 2017, 11, 481. [CrossRef] [PubMed]

132. Wang, T.; Qin, L.; Liu, B.; Liu, Y.; Wilson, B.; Eling, T.E.; Langenbach, R.; Taniura, S.; Hong, J.S. Role of reactive oxygen species in LPS-induced production of prostaglandin E2 in microglia. J. Neurochem. 2004, 88, 939-947. [CrossRef]

133. Salvemini, D.; Little, J.W.; Doyle, T.; Neumann, W.L. Roles of reactive oxygen and nitrogen species in pain. Free Radic Biol. Med. 2011, 51, 951-966. [CrossRef]

134. Lees, J.; Makker, P.G.; Tonkin, R.S.; Abdulla, M.; Park, S.B.; Goldstein, D.; Moalem-Taylor, G. Immune-mediated processes implicated in chemotherapy-induced peripheral neuropathy. Eur. J. Cancer 2017, 73, 22-29. [CrossRef]

135. So, Y.T. Immune-mediated neuropathies. Continuum. Minneap. Minn. 2012, 18, 85-105. [CrossRef] [PubMed]

136. Liao, B.; Shroff, S.; Kamiya-Matsuoka, C.; Tummala, S. Atypical neurological complications of ipilimumab therapy in patients with metastatic melanoma. Neuro Oncol. 2014, 16, 589-593. [CrossRef]

137. Thaipisuttikul, I.; Chapman, P.; Avila, E.K. Peripheral neuropathy associated with ipilimumab: A report of 2 cases. J. Immunother. 2015, 38, 77-79. [CrossRef]

138. Johnson, D.B.; Manouchehri, A.; Haugh, A.M.; Quach, H.T.; Balko, J.M.; Lebrun-Vignes, B.; Mammen, A.; Moslehi, J.J.; Salem, J.E. Neurologic toxicity associated with immune checkpoint inhibitors: A pharmacovigilance study. J. Immunother. Cancer 2019, 7, 134. [CrossRef]

139. Gaudy-Marqueste, C.; Monestier, S.; Franques, J.; Cantais, E.; Richard, M.A.; Grob, J.J. A severe case of ipilimumab-induced guillain-barré syndrome revealed by an occlusive enteric neuropathy: A differential diagnosis for ipilimumab-induced colitis. $J$. Immunother. 2013, 36, 77-78. [CrossRef] [PubMed]

140. Kemar, E.; Green, D.O.; Anna, M.; Levine, B.S.; Jayne, H.; Ward, D.O.; David, I.; Kaufman, D.O. GQ1b-Seronegative Miller Fisher Syndrome Associated with Pembrolizumab. J. Neuro Ophthalmol. 2019, 39, 394-396. [CrossRef]

141. Kolb, N.A.; Trevino, C.R.; Waheed, W.; Sobhani, F.; Landry, K.K.; Thomas, A.A.; Hehir, M. Neuromuscular complications of immune checkpoint inhibitor therapy. Muscle Nerve 2018. [CrossRef]

142. Moudgil, S.S.; Riggs, J.E. Fulminant peripheral neuropathy with severe quadriparesis associated with vincristine therapy. Ann. Pharmacother. 2000, 34, 1136-1138. [CrossRef]

143. Jariwal, R.; Shoua, B.; Sabetian, K.; Natarajan, P.; Cobos, E. Unmasking a case of asymptomatic Charcot-Marie-Tooth disease (CMT1A) with vincristine. J. Investig. Med. High. Impact. Case Rep. 2018, 6, 2324709618758349. [CrossRef]

144. Stübgen, J.P. Tumor necrosis factor-alpha antagonists and neuropathy. Muscle Nerve 2008, 37, 281-292. [CrossRef]

145. Ravaglia, S.; Corso, A.; Piccolo, G.; Lozza, A.; Alfonsi, E.; Mangiacavalli, S.; Varettoni, M.; Zappasodi, P.; Moglia, A.; Lazzarino, M.; et al. Immune-mediated neuropathies in myeloma patients treated with bortezomib. Clin. Neurophysiol. 2008, 119, $2507-2512$. [CrossRef]

146. Christodoulou, C.; Anastasopoulos, D.; Visvikis, A.; Mellou, S.; Detsi, I.; Tsiakalos, G.; Pateli, A.; Klouvas, G.; Papadimitriou, A.; Skarlos, D.V. Guillain-Barré syndrome in a patient with metastatic colon cancer receiving oxaliplatin-based chemotherapy. Anticancer Drugs 2004, 15, 997-999. [CrossRef] [PubMed]

147. Pappa, E.; Berzero, G.; Herlin, B.; Ricard, D.; Tafani, C.; Devic, P.; Maillet, D.; Borden, A.; Viala, K.; Maisonobe, T.; et al. Guillain-Barré syndrome during platinum-based chemotherapy: A case series and review of the literature. Oncologist 2020, 25, e194-e197. [CrossRef]

148. Yoon, J.Y.; Nam, T.S.; Kim, M.K.; Hwang, J.E.; Shim, H.J.; Cho, S.H.; Chung, I.J.; Bae, W.K. Acute inflammatory demyelinating polyradiculoneuropathy in a patient receiving oxaliplatin-based chemotherapy. Asia Pac. J. Clin. Oncol. 2012, 8, 201-214. [CrossRef] [PubMed]

149. Ueda, M.; Kusunoki, S. Autoimmune neuropathies: Diagnosis, treatment, and recent topics. Brain Nerve 2011, 63, 549-555. [PubMed]

150. Hanewinckel, R.; Ikram, M.A.; Van Doorn, P.A. Peripheral neuropathies. Handb. Clin. Neurol. 2016, 138, 263-282. [CrossRef] [PubMed]

151. Broers, M.C.; Bunschoten, C.; Nieboer, D.; Lingsma, H.F.; Jacobs, B.C. Incidence and prevalence of chronic inflammatory demyelinating polyradiculoneuropathy: A systematic review and meta-analysis. Neuroepidemiology 2019, 52, 161-172. [CrossRef]

152. Aral, Y.Z.; Gursel, T.; Ozturk, G.; Serdaroglu, A. Guillain-Barré syndrome in a child with acute lymphoblastic leukemia. Pediatr. Hematol. Oncol. 2001, 18, 343-346. [CrossRef]

153. Miller, S.D.; Olson, J.K.; Croxford, J.L. Multiple pathways to induction of virus-induced autoimmune demyelination: Lessons from Theiler's virus infection. J. Autoimmun. 2001, 16, 219-227. [CrossRef]

154. Olson, J.K.; Eagar, T.N.; Miller, S.D. Functional activation of myelin-specific T cells by virus-induced molecular mimicry. J. Immunol. 2002, 169, 2719-2726. [CrossRef] [PubMed] 
155. Hughes, R.A.; Hadden, R.D.; Gregson, N.A.; Smith, K.J. Pathogenesis of Guillain-Barré syndrome. J. Neuroimmunol. 1999, 100, 74-97. [CrossRef]

156. Dalakas, M.C. Neurological complications of immune checkpoint inhibitors: What happens when you 'take the brakes off' the immune system. Ther. Adv. Neurol. Disord. 2018, 14, 1756286418799864. [CrossRef]

157. Zimmer, L.; Goldinger, S.M.; Hofmann, L.; Loquai, C.; Ugurel, S.; Thomas, I.; Schmidgen, M.I.; Gutzmer, R.; Utikal, J.S.; Göppner, D.; et al. Neurological, respiratory, musculoskeletal, cardiac and ocular side-effects of anti-PD-1 therapy. Eur. J. Cancer 2016, 60, 210-225. [CrossRef]

158. Re, D.; Schwenk, A.; Hegener, P.; Bamborschke, S.; Diehl, V.; Tesch, H. Guillain-Barré syndrome in a patient with non-Hodgkin's lymphoma. Ann. Oncol. 2000, 11, 217-220. [CrossRef]

159. Tazi, I.; Nafil, H.; Zaoui, S.; Mahmal, L. Fatal vincristine-induced acute neurotoxicity mimicking Guillain-Barré syndrome. J. Cancer Res. Ther. 2013, 9, 335-336. [CrossRef]

160. Bahl, A.; Chakrabarty, B.; Gulati, S.; Raju, K.N.; Raja, A.; Bakhshi, S. Acute onset flaccid quadriparesis in pediatric non-Hodgkin lymphoma: Vincristine induced or Guillain-Barré syndrome? Pediatr. Blood Cancer 2010, 55, 1234-1235. [CrossRef]

161. Hogan-Dann, C.M.; Fellmeth, W.G.; McGuire, S.A.; Kiley, V.A. Polyneuropathy following vincristine therapy in two patients with Charcot-Marie-Tooth syndrome. JAMA 1984, 252, 2862-2863. [CrossRef] [PubMed]

162. Igarashi, M.; Thompson, E.I.; Rivera, G.K. Vincristine neuropathy in type I and type II Charcot-Marie-Tooth disease (hereditary motor sensory neuropathy). Med. Pediatr. Oncol. 1995, 25, 113-116. [CrossRef]

163. Okuhara, Y.; Shinomiya, R.; Peng, F.; Kamei, N.; Kurashige, T.; Yokota, K.; Ochi, M. Direct effect of radiation on the peripheral nerve in a rat model. J. Plast. Surg. Hand. Surg. 2014, 48, 276-280. [CrossRef]

164. Killer, H.E.; Hess, K. Natural history of radiation-induced brachial plexopathy compared with surgically treated patients. J. Neurol. 1990, 237, 247-250. [CrossRef]

165. Gosk, J.; Rutowski, R.; Reichert, P.; Rabczyński, J. Radiation-induced brachial plexus neuropathy—Aetiopathogenesis, risk factors, differential diagnostics, symptoms and treatment. Folia Neuropathol. 2007, 45, 26-30. [PubMed]

166. Delanian, S.; Lefaix, J.L.; Pradat, P.F. Radiation-induced neuropathy in cancer survivors. Radiother. Oncol. 2012, 105, $273-282$. [CrossRef]

167. Ducray, F.; Guillevin, R.; Psimaras, D.; Sanson, M.; Mokhtari, K.; Delanian, S.; Navarro, S.; Maisonobe, T.; Cornu, P.; Hoang-Xuan, K.; et al. Postradiation lumbosacral radiculopathy with spinal root cavernomas mimicking carcinomatous meningitis. Neuro Oncol. 2008, 10, 1035-1039. [CrossRef]

168. Wadd, N.J.; Lucraft, H.H. Brachial plexus neuropathy following mantle radiotherapy. Clin. Oncol. R Coll. Radiol. 1998, 10, 399-400. [CrossRef]

169. Kori, S.H.; Foley, K.M.; Posner, J.B. Brachial plexus lesions in patients with cancer: 100 cases. Neurology 1981, 31, 45-50. [CrossRef]

170. Olsen, N.K.; Pfeiffer, P.; Johannsen, L.; Schrøder, H.; Rose, C. Radiation-induced brachial plexopathy: Neurological follow-up in 161 recurrence-free breast cancer patients. Int. J. Radiat. Oncol. Biol. Phys. 1993, 26, 43-49. [CrossRef]

171. Glass, J.P.; Pettigrew, L.C.; Maor, M. Plexopathy induced by radiation therapy. Neurology 1985, 35, 1261. [CrossRef] [PubMed]

172. Bowen, J.; Gregory, R.; Squier, M.; Donaghy, M. The post-irradiation lower motor neuron syndrome neuronopathy or radiculopathy? Brain 1996, 119, 1429-1439. [CrossRef]

173. Thomas, J.E.; Cascino, T.L.; Earle, J.D. Differential diagnosis between radiation and tumor plexopathy of the pelvis. Neurology 1985, 35, 1-7. [CrossRef]

174. Dropcho, E.J. Neurotoxicity of radiation therapy. Neurol. Clin. 2010, 28, 217-234. [CrossRef] [PubMed]

175. Soto, O. Radiation-induced conduction block: Resolution following anticoagulant therapy. Muscle Nerve 2005, 31, 642-645. [CrossRef]

176. Bennett, M.H.; Feldmeier, J.; Hampson, N.B.; Smee, R.; Milross, C. Hyperbaric oxygen therapy for late radiation tissue injury. Cochrane Database Syst. Rev. 2016, 4, CD005005. [CrossRef]

177. Hamama, S.; Gilbert-Sirieix, M.; Vozenin, M.C.; Delanian, S. Radiation-induced enteropathy: Molecular basis of pentoxifyllinevitamin E anti-fibrotic effect involved TGF- $\beta 1$ cascade inhibition. Radiother. Oncol. 2012, 105, 305-312. [CrossRef]

178. Williamson, R.; Kondziolka, D.; Kanaan, H.; Lunsford, L.D.; Flickinger, J.C. Adverse radiation effects after radiosurgery may benefit from oral vitamin E and pentoxifylline therapy: A pilot study. Stereotact. Funct. Neurosurg. 2008, 86, 359-366. [CrossRef] [PubMed]

179. Delanian, S.; Lefaix, J.L.; Maisonobe, T.; Salachas, F.; Pradat, P.F. Significant clinical improvement in radiation-induced lumbosacral polyradiculopathy by a treatment combining pentoxifylline, tocopherol, and clodronate (Pentoclo). J. Neurol. Sci. 2008, 275, 164-166. [CrossRef]

180. Spencer, N.J.; Hu, H. Enteric nervous system: Sensory transduction, neural circuits and gastrointestinal motility. Nat. Rev. Gastroenterol. Hepatol. 2020, 17, 338-351. [CrossRef]

181. Di Nardo, G.; Blandizzi, C.; Volta, U.; Colucci, R.; Stanghellini, V.; Barbara, G.; Del Tacca, M.; Tonini, M.; Corinaldesi, R.; De Giorgio, R. Review article: Molecular, pathological and therapeutic features of human enteric neuropathies. Aliment. Pharmacol. Ther. 2008, 28, 25-42. [CrossRef]

182. Fleming, M.A., 2nd; Ehsan, L.; Moore, S.R.; Levin, D.E. The Enteric Nervous System and Its Emerging Role as a Therapeutic Target. Gastroenterol. Res. Pract. 2020, 2020, 8024171. [CrossRef] 
183. McQuade, R.M.; Al Thaalibi, M.; Nurgali, K. Impact of chemotherapy-induced enteric nervous system toxicity on gastrointestinal mucositis. Curr. Opin. Support. Palliat. Care. 2020, 14, 293-300. [CrossRef] [PubMed]

184. Wafai, L.; Taher, M.; Jovanovska, V.; Bornstein, J.C.; Dass, C.R.; Nurgali, K. Effects of oxaliplatin on mouse myenteric neurons and colonic motility. Front. Neurosci. 2013, 7, 30. [CrossRef] [PubMed]

185. Pini, A.; Garella, R.; Idrizaj, E.; Calosi, L.; Baccari, M.C.; Vannucchi, M.G. Glucagon-like peptide 2 counteracts the mucosal damage and the neuropathy induced by chronic treatment with cisplatin in the mouse gastric fundus. Neurogastroenterol. Motil. 2016, 28, 206-216. [CrossRef]

186. Vera, G.; Castillo, M.; Cabezos, P.A.; Chiarlone, A.; Martín, M.I.; Gori, A.; Pasquinelli, G.; Barbara, G.; Stanghellini, V.; Corinaldesi, R.; et al. Enteric neuropathy evoked by repeated cisplatin in the rat. Neurogastroenterol. Motil. 2011, 23, 370-378, e162-e163. [CrossRef]

187. McQuade, R.M.; Carbone, S.E.; Stojanovska, V.; Rahman, A.; Gwynne, R.M.; Robinson, A.M.; Goodman, C.A.; Bornstein, J.C.; Nurgali, K. Role of oxidative stress in oxaliplatin-induced enteric neuropathy and colonic dysmotility in mice. Br. J. Pharmacol. 2016, 173, 3502-3521. [CrossRef]

188. Robinson, A.M.; Stojanovska, V.; Rahman, A.A.; McQuade, R.M.; Senior, P.V.; Nurgali, K. Effects of oxaliplatin treatment on the enteric glial cells and neurons in the mouse ileum. J. Histochem. Cytochem. 2016, 64, 530-545. [CrossRef]

189. McQuade, R.M.; Stojanovska, V.; Stavely, R.; Timpani, C.; Petersen, A.C.; Abalo, R.; Bornstein, J.C.; Rybalka, E.; Nurgali, K. Oxaliplatin-induced enteric neuronal loss and intestinal dysfunction is prevented by co-treatment with BGP-15. Br. J. Pharmacol. 2018, 175, 656-677. [CrossRef]

190. Donald, E.L.; Stojanovska, L.; Apostolopoulos, V.; Nurgali, K. Resveratrol alleviates oxidative damage in enteric neurons and associated gastrointestinal dysfunction caused by chemotherapeutic agent oxaliplatin. Maturitas 2017, 105, 100-106. [CrossRef]

191. McQuade, R.M.; Stojanovska, V.; Donald, E.; Abalo, R.; Bornstein, J.C.; Nurgali, K. Gastrointestinal dysfunction and enteric neurotoxicity following treatment with anticancer chemotherapeutic agent 5-fluorouracil. Neurogastroenterol. Motil. 2016, 28, 1861-1875. [CrossRef]

192. McQuade, R.M.; Stojanovska, V.; Donald, E.L.; Rahman, A.A.; Campelj, D.G.; Abalo, R.; Rybalka, E.; Bornstein, J.C.; Nurgali, K. Irinotecan-induced gastrointestinal dysfunction Is associated with enteric neuropathy, but increased numbers of cholinergic myenteric neurons. Front. Physiol. 2017, 8, 391. [CrossRef]

193. López-Gómez, L.; Díaz-Ruano, S.; Girón, R.; López-Pérez, A.E.; Vera, G.; Herradón Pliego, E.; López-Miranda, V.; Nurgali, K.; Martín-Fontelles, M.I.; Uranga, J.A.; et al. Preclinical evaluation of the effects on the gastrointestinal tract of the antineoplastic drug vincristine repeatedly administered to rats. Neurogastroenterol. Motil. 2018, 30, e13399. [CrossRef]

194. Hooper, L.V.; Littman, D.R.; Macpherson, A.J. Interactions between the microbiota and the immune system. Science 2012, 336, 1268-1273. [CrossRef]

195. Al-Chaer, E.D.; Kawasaki, M.; Pasricha, P.J. A new model of chronic visceral hypersensitivity in adult rats induced by colon irritation during postnatal development. Gastroenterology 2000, 119, 1276-1285. [CrossRef]

196. Bolton, C.F.; Gilbert, J.J.; Hahn, A.F.; Sibbald, W.J. Polyneuropathy in critically ill patients. J. Neurol. Neurosurg. Psychiatry 1984, 47, 1223-1231. [CrossRef]

197. Charisius, J.; Stiefel, M.; Merkel, N.; Kornhuber, M.; Haase, R.; Kramm, C.M. Critical illness polyneuropathy: A rare but serious adverse event in pediatric oncology. Pediatr. Blood Cancer 2010, 54, 161-165. [CrossRef]

198. Williams, S.; Horrocks, I.A.; Ouvrier, R.A.; Gillis, J.; Ryan, M.M. Critical illness polyneuropathy and myopathy in pediatric intensive care: A review. Pediatr. Crit. Care Med. 2007, 8, 18-22. [CrossRef]

199. Bolton, C.F. Neuromuscular manifestations of critical illness. Muscle Nerve 2005, 32, 140-163. [CrossRef]

200. Tabarki, B.; Coffiniéres, A.; Van Den Bergh, P.; Huault, G.; Landrieu, P.; Sébire, G. Critical illness neuromuscular disease: Clinical, electrophysiological, and prognostic aspects. Arch. Dis. Child. 2002, 86, 103-107. [CrossRef]

201. Hirabayashi, K.; Shiohara, M.; Suzuki, T.; Saito, S.; Tanaka, M.; Yanagisawa, R.; Tsuruta, G.; Fukuyama, T.; Hidaka, Y.; Nakazawa, Y.; et al. Critical illness polyneuropathy and myopathy caused by Bacillus cereus sepsis in acute lymphoblastic leukemia. $J$. Pediatr. Hematol. Oncol. 2012, 34, 10-113. [CrossRef]

202. van Mook, W.N.; Hulsewé-Evers, R.P. Critical illness polyneuropathy. Curr. Opin. Crit. Care 2002, 8, 302-310. [CrossRef] [PubMed] 